\title{
Nociceptor Translational Profiling Reveals the Ragulator-Rag GTPase Complex as a Critical Generator of Neuropathic Pain
}

\author{
Salim Megat, ${ }^{1,2}$ Pradipta R. Ray, ${ }^{1,2}$ Jamie K. Moy, ${ }^{1}$ Tzu-Fang Lou, ${ }^{3}$ Paulino Barragán-Iglesias, ${ }^{1,2}$ ํㅏan Li, ${ }^{4}$ \\ (1) Grishma Pradhan, ${ }^{1,2}$ Andi Wanghzou, ${ }^{1,2}$ Ayesha Ahmad, ${ }^{1,2}$ @Michael D. Burton, ${ }^{1,2}$ Robert Y. North, ${ }^{4}$

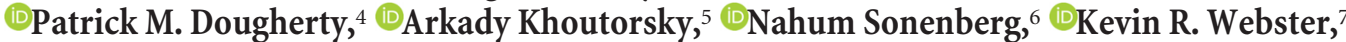 \\ Gregory Dussor, ${ }^{1,2} \mathbb{D}^{-}$Zachary T. Campbell, ${ }^{2,3}$ and ${ }^{-T h e o d o r e ~ J . ~ P r i c e ~}{ }^{1,2}$ \\ ${ }^{1}$ University of Texas at Dallas, School of Behavioral and Brain Sciences, 800 Campbell Rd, Richardson, Texas, 75080, ${ }^{2}$ University of Texas at Dallas, Center \\ for Advanced Pain Studies, 800 Campbell Rd, Richardson, Texas, 75080, ${ }^{3}$ University of Texas at Dallas, Department of Biological Sciences, 800 Campbell Rd, \\ Richardson, Texas, 75080, ${ }^{4}$ University of Texas M.D. Anderson Cancer Center, Department of Anesthesia and Pain Medicine, 1400 Holcombe Boulevard, \\ Houston, TX 77030, ${ }^{5}$ McGill University, Department of Anesthesia, 001 Boulevard Décarie C05.2000, Montréal, QC H4A 3J1, Canada, ${ }^{6}$ McGill University, \\ Goodman Cancer Research Center, Department of Biochemistry, 1160 Pine Ave W, Montreal, QC H3A 1A3, Canada, and 7 eFFECTOR Therapeutics, 11180 \\ Roselle St, San Diego, CA 92121
}

Nociceptors, sensory neurons in the DRG that detect damaging or potentially damaging stimuli, are key drivers of neuropathic pain. Injury to these neurons causes activation of translation regulation signaling, including the mechanistic target of rapamycin complex 1 (mTORC1) and mitogen-activated protein kinase interacting kinase (MNK) eukaryotic initiation factor (eIF) 4E pathways. This is a mechanism driving changes in excitability of nociceptors that is critical for the generation of chronic pain states; however, the mRNAs that are translated to lead to this plasticity have not been elucidated. To address this gap in knowledge, we used translating ribosome affinity purification in male and female mice to comprehensively characterize mRNA translation in Scn10a-positive nociceptors in chemotherapy-induced neuropathic pain (CIPN) caused by paclitaxel treatment. This unbiased method creates a new resource for the field, confirms many findings in the CIPN literature and also find extensive evidence for new target mechanisms that may cause CIPN. We provide evidence that an underlying mechanism of CIPN is sustained mTORC1 activation driven by MNK1-eIF4E signaling. RagA, a GTPase controlling mTORC1 activity, is identified as a novel target of MNK1-eIF4E signaling. This demonstrates a novel translation regulation signaling circuit wherein MNK1-eIF4E activity drives mTORC1 via control of RagA translation. CIPN and RagA translation are strongly attenuated by genetic ablation of eIF4E phosphorylation, MNK1 elimination or treatment with the MNK inhibitor eFT508. We identify a novel translational circuit for the genesis of neuropathic pain caused by chemotherapy with important implications for therapeutics.

Key words: eIF4E; mTOR; neuropathic pain; nociceptor; TRAP

\section{Significance Statement}

Neuropathic pain affects up to $10 \%$ of the population, but its underlying mechanisms are incompletely understood, leading to poor treatment outcomes. We used translating ribosome affinity purification technology to create a comprehensive translational profile of DRG nociceptors in naive mice and at the peak of neuropathic pain induced by paclitaxel treatment. We reveal new insight into how mechanistic target of rapamycin complex 1 is activated in neuropathic pain pointing to a key role of MNK1-eIF4Emediated translation of a complex of mRNAs that control mechanistic target of rapamycin complex 1 signaling at the surface of the lysosome. We validate this finding using genetic and pharmacological techniques. Our work strongly suggests that MNK1-eIF4E signaling drives CIPN and that a drug in human clinical trials, eFT508, may be a new therapeutic for neuropathic pain.

\section{Introduction}

Neuropathic pain is a devastating disease with extraordinarily poor treatment outcomes. Existing first-line treatments produce only $30 \%$ pain relief in the majority of patients (Finnerup et al., 2015). Neuropathic pain is associated with important neuron-

J.K.M., T.-F.L., P.B.-I., Y.L., G.P., A.A., A.W., M.D.B., and R.Y.N. performed research; K.R.W. contributed unpublished reagents/analytic tools; S.M., P.R.R., J.K.M., P.B.-I., A.W., and T.J.P. analyzed data; S.M., Z.T.C., and T.J.P. wrote the paper.

This work was supported by National Institutes of Health Grants R01NS065926 to T.J.P., R01NS098826 to T.J.P. and G.D., R01CA200263 to P.M.D., and R01NS100788 to Z.T.C., University of Texas STARS program to T.J.P. and G.D.,

H.E.B. Professorship in Cancer Research to P.M.D., and a postdoctoral CONACYT fellowship program to P.B.-I. 
immune interactions (Ji et al., 2016) and neuronal plasticity in the PNS (Campbell and Meyer, 2006; Gereau et al., 2014; Price and Gold, 2018; Price et al., 2018) and CNS (Denk et al., 2014). Compelling evidence from animal models and human studies indicates that PNS-driven, sensory neuronal input to the CNS is required for neuropathic pain (Haroutounian et al., 2014, 2018; Vaso et al., 2014). This has led to the view that peripheral pain sensing neurons, called nociceptors, are a critical cellular origin of pain caused by neuropathies (Campbell and Meyer, 2006; Gold and Gebhart, 2010; Haroutounian et al., 2014, 2018; Vaso et al., 2014; Yang et al., 2014; Price and Gold, 2018). Recent studies using optogenetic methods support this view (Daou et al., 2016; Cowie et al., 2018). There are many different causes of neuropathic pain, including trauma to peripheral nerves, metabolic disease, and toxicities produced by drug treatment. As advances in cancer treatment efficacy have transformed treatment of this diverse disease, incidence and duration of chemotherapyinduced peripheral neuropathy (CIPN) have increased (Seretny et al., 2014; Ma et al., 2018). CIPN is the primary dose-limiting side effect of cancer treatment, and no drugs are approved to treat this form of neuropathic pain (Ma et al., 2018). A primary aim of the work described here was to understand the regulatory changes in nociceptors that could contribute to CIPN using an unbiased, translational profiling method.

The dynamics of nociceptor-specific gene expression in vivo in a neuropathic pain model have not been described at a genomewide scale. Several studies have used RNA sequencing technology to gain insight into the DRG transcriptome and how it changes in neuropathic pain models (Manteniotis et al., 2013; Thakur et al., 2014; Hu et al., 2016; Lopes et al., 2017a; Ray et al., 2018). These studies have provided important details on immune cell infiltration into the DRG after peripheral nerve injury and how this may provide insight into sexually dimorphic mechanisms of neuropathic pain (Lopes et al., 2017b). Other studies have used single neuron sequencing on the DRG after nerve injury to provide insight into mechanisms driving neuropathic pain (Hu et al., 2016). These invaluable resources fail to capture the translational status of a given transcript. This is important because translation regulation plays a critical role in sensitization of nociceptors in response to a broad variety of factors, including nerve injury (Khoutorsky and Price, 2018). Ribosome tagging (Heiman et al., 2008) and ribosome profiling (Ingolia et al., 2012) methods have been developed to overcome this technical challenge on a genomewide scale. Ribosome profiling was recently used in a neuropathic pain model on the DRG and spinal cord (Uttam et al., 2018), but this method does not afford cell type specificity. We used the translating ribosome affinity purification (TRAP) technology (Heiman et al., 2008), using the Nav1.8 ${ }^{\mathrm{Cre}}$ mouse to achieve sensory neuron-specific ribosome tagging with enrichment in the nociceptor population. We used these Nav1.8-TRAP mice to identify transcripts associated with ribosomes specifically expressed in Nav1.8-positive neurons, most of which are nociceptors, isolated from animals with or without paclitaxel-induced CIPN. This tool pinpoints pathology in a translation signaling network that centers around RagA and mechanistic target of

K.R.W. is an employee of eFFECTOR Therapeutics. The remaining authors declare no competing financial interests.

Correspondence should be addressed to either of the following: Dr. Theodore J. Price, University of Texas at Dallas, School of Behavioral and Brain Sciences, 800 Campbell Rd, Richardson, Texas, 75080, E-mail: theodore.price@utdallas.edu; or Dr. Zachary T. Campbell, University of Texas at Dallas, Department of Biological Sciences, 800 Campbell Rd, Richardson, Texas, 75080, E-mail: zachary.campbell@utdallas.edu.

https://doi.org/10.1523/JNEUROSCI.2661-18.2018

Copyright $\odot 2019$ the authors $\quad 0270-6474 / 19 / 390394-19 \$ 15.00 / 0$ rapamycin complex 1 (mTORC1) that is driven by mitogenactivated protein kinase interacting kinase (MNK) and eukaryotic initiation factor (eIF) 4E-driven translation of the Rraga mRNA encoding the RagA protein. Using mouse genetics and pharmacology, we demonstrate how this insight provides new strategies for the potential development of disease-modifying agents for neuropathic pain treatment, a debilitating and pervasive clinical problem.

\section{Materials and Methods}

Antibodies for TRAP (HtzGFP-19F7 and HtzGFP-19C8) were obtained from Sloan Memorial Kettering Centre, after establishing Material Transfer Agreements with the laboratory of Prof. Nathaniel Heintz at the Rockefeller University. All animal procedures were approved by the Institutional Animal Care and Use Committee of University of Texas at Dallas.

\section{Transgenic animals}

Nav1.8 $8^{\text {cre }} /$ Rosa2 $26^{\text {sTRAP }}$ mice. Rosa26 $6^{\text {fsTRAP }}$ mice were generated as described previously (Zhou et al., 2013) and purchased from The Jackson Laboratory (stock \#022367). Transgenic mice expressing Cre recombinase under the control of the Scn10a (Nav1.8) promoter were obtained initially from Professor John Wood (University College London) but are commercially available from Infrafrontier (EMMA ID: 04582). The initial characterization of these mice demonstrated that the introduction of the Cre recombinase in heterozygous animals does not affect pain behavior, and their DRG neurons have normal electrophysiological properties (Stirling et al., 2005). Nav1.8 ${ }^{\text {cre }}$ mice on a C57BL/6J genetic background were maintained and bred at the University of Texas at Dallas. Upon arrival, Rosa $26^{\text {fsTRAP }}$ mice were crossed to Nav1. $8^{\text {cre }}$ to generate the Nav1.8-TRAP mice that express a fused EGFP-L10a protein in Nav1.8expressing neurons. All experiments were performed using male and female littermates 8-12 weeks old. Mice were group housed (4 maximum) in nonenvironmentally enriched cages with food and water ad libitum in a $12 \mathrm{~h}$ light-dark cycle. Room temperature was maintained at $21 \pm 2^{\circ} \mathrm{C}$.

eIF4E ${ }^{\text {S209A }}$ and $\mathrm{Mnk1}^{-1-}$ mice. eIF4E $\mathrm{E}^{\mathrm{S} 209 \mathrm{~A}}$ mice on a C57BL/6J background were generated in the Sonenberg laboratory at McGill University, as described previously (Furic et al., 2010) and bred at the University of Texas Dallas to generate experimental animals. All animals were genotyped using DNA from ear clips taken at the time of weaning, and all animals were backcrossed to C57BL/6J background for at least 10 generations before experiments. Behavioral experiments using eIF4E ${ }^{S 209 A}$ and WT mice were performed using mice between the ages of 8 and 12 weeks.

$M n k 1^{-1-}$ mice on a C57BL/6J background were provided by the Sonenberg laboratory at McGill University and generated as described previously (Ueda et al., 2004).

\section{TRAP}

Nav1.8-TRAP male and female mice were decapitated and DRGs rapidly dissected in ice-cold dissection buffer ( $1 \times$ HBSS (Invitrogen 14065006), $2.5 \mathrm{~mm}$ HEPES, $35 \mathrm{~mm}$ glucose, $4 \mathrm{~mm} \mathrm{NaHCO} 3,100 \mu \mathrm{g} / \mathrm{ml}$ cycloheximide, $0.001 \mathrm{~V} 2 \mathrm{mg} / \mathrm{ml}$ emetine). DRGs were transferred to ice-cold polysome buffer (20 mM HEPES, $12 \mathrm{~mm} \mathrm{MgCl}_{2}, 150 \mathrm{~mm} \mathrm{KCl,} 0.5 \mathrm{~mm}$ DTT, $100 \mu \mathrm{g} / \mathrm{ml}$ cycloheximide, $20 \mu \mathrm{g} / \mathrm{ml}$ emetine, $40 \mathrm{U} / \mathrm{ml}$ SUPERase IN (Promega), $1 \mu \mathrm{l}$ DNase and protease inhibitor and homogenized using a Dounce homogenizer. Samples were centrifuged at $3000 \times g$ for $10 \mathrm{~min}$ to prepare post-nuclear fraction (S1). Then, $1 \% \mathrm{NP}-40$ and $30 \mathrm{~m}$ cyclohexamide DHPC were added to the $\mathrm{S} 1$ fraction and then centrifuged at $15,000 \times g$ for $15 \mathrm{~min}$ to generate a postmitochondrial fraction (S20). A $200 \mu \mathrm{l}$ sample of S20 was removed for use as input, and $800 \mu \mathrm{l}$ of S20 was incubated with protein G-coated Dynabeads (Invitrogen) bound to $50 \mu \mathrm{g}$ of anti-GFP antibodies (HtzGFP-19F7 and HtzGFP-19C8, Memorial Sloan Kettering Center) for $3 \mathrm{~h}$ at $4^{\circ} \mathrm{C}$ with end-over-end mixing. Anti-GFP beads were washed with high salt buffer $(20 \mathrm{~mm}$ HEPES, $5 \mathrm{~mm}$ $\mathrm{MgCl}_{2}, 350 \mathrm{~mm} \mathrm{KCl}, 1 \% \mathrm{NP}-40,0.5 \mathrm{~mm}$ DTT, and $100 \mu \mathrm{g} / \mathrm{ml}$ cycloheximide), and RNA was eluted from all samples using a Direct-zol kit (Zymo Research) according to the manufacturer's instructions. RNA yield was quantified using a Nanodrop system (Thermo Fisher Scien- 
Table 1. Details of each biological replicate showing the next-generation assay type, input/immunoprecipitation (IP) pairing between replicates, number of mice used and their sex, and alignment quality statistics (number of mapped reads and number of reads mapping to many [ $>20]$ places in the genome)

\begin{tabular}{|c|c|c|c|c|c|}
\hline \multirow[b]{2}{*}{ Internal ID } & \multicolumn{3}{|l|}{ Biosample details } & \multicolumn{2}{|l|}{ Alignment quality } \\
\hline & Library type & Biosample no. & Animal makeup & No. of reads mapped & High ambiguity mapping $(>20)$ \\
\hline IN2 & Vehicle input & 1 & $2 \mathrm{M}+2 \mathrm{~F}$ & $38,427,220$ & 220,558 \\
\hline IN3 & Vehicle input & 2 & $2 \mathrm{M}+2 \mathrm{~F}$ & $23,854,278$ & 134,944 \\
\hline IN5 & Vehicle input & 3 & $2 \mathrm{M}+2 \mathrm{~F}$ & $37,406,138$ & 304,324 \\
\hline IN6 & Vehicle input & 4 & $2 \mathrm{M}+2 \mathrm{~F}$ & $18,419,246$ & 71,160 \\
\hline IP2 & Vehicle IP & 1 & $2 \mathrm{M}+2 \mathrm{~F}$ & $25,953,906$ & 137,013 \\
\hline IP3 & Vehicle IP & 2 & $2 \mathrm{M}+2 \mathrm{~F}$ & $34,757,473$ & 207,750 \\
\hline IP5 & Vehicle IP & 3 & $2 \mathrm{M}+2 \mathrm{~F}$ & $27,206,084$ & 185,472 \\
\hline IP6 & Vehicle IP & 4 & $2 \mathrm{M}+2 \mathrm{~F}$ & $20,008,549$ & 125,338 \\
\hline IN1_PAC & Paclitaxel-treated input & 5 & $2 \mathrm{M}+2 \mathrm{~F}$ & $29,990,168$ & 287,912 \\
\hline IN3_PAC & Paclitaxel-treated input & 6 & $2 \mathrm{M}+2 \mathrm{~F}$ & $37,060,526$ & 316,835 \\
\hline IN4 + 7_PAC & Paclitaxel-treated input & 7 & $6 \mathrm{M}+2 \mathrm{~F}$ & $44,559,848$ & 457,455 \\
\hline IN8_PAC & Paclitaxel-treated input & 8 & $2 \mathrm{M}+2 \mathrm{~F}$ & $21,387,544$ & 166,589 \\
\hline IP1_PAC & Paclitaxel-treated IP & 5 & $2 \mathrm{M}+2 \mathrm{~F}$ & $19,369,857$ & 126,590 \\
\hline IP3_PAC & Paclitaxel-treated IP & 6 & $2 \mathrm{M}+2 \mathrm{~F}$ & $43,695,404$ & 288,640 \\
\hline IP4 + 7_PAC & Paclitaxel-treated IP & 7 & $6 \mathrm{M}+2 \mathrm{~F}$ & $34,048,549$ & 382,070 \\
\hline IP8_PAC & Paclitaxel-treated IP & 8 & $2 \mathrm{M}+2 \mathrm{~F}$ & $20,293,108$ & 188,669 \\
\hline
\end{tabular}

tific), and RNA quality was determined by a fragment analyzer (Advanced Analytical Technologies).

\section{Library generation and sequencing}

Libraries were generated from $100 \mathrm{ng}$ to $1 \mu \mathrm{g}$ of total RNA using Quantseq 3' mRNA-Seq library kit (Lexogen) with RiboCop rRNA depletion kit (Lexogen) treatment according to the manufacturer's protocols. The endpoint PCR amplification cycle number for each sample was determined by qPCR assay with PCR Add-on kit for Illumina (Lexogen). The cycle number was selected when the fluorescence value reached $33 \%$ of the maximum for each sample. Purified libraries were quantified by Qubit (Invitrogen), and the average size was determined by fragment analyzer (Advanced Analytical Technologies) with high-sensitivity NGS fragment analysis kit. Libraries were then sequenced on an Illumina NextSeq500 Sequencer using 50 bp single-end reads.

Sequence files generated by the Illumina NextSeq500 Sequencer were downloaded from BaseSpace. An Initial quality check using FastQC 0.11.5 (Babraham Bioinformatics) was done on the sequencing files, and then trimming was performed on the server with the FASTQ Toolkit. Sequences were trimmed with optimized parameters ( 13 bases from $3^{\prime}$ end, 17 bases from $5^{\prime}$ end, and any poly-adenine longer than 2 bases from the $3^{\prime}$ side). Trimming parameters were optimized based on FastQC results and mapping rate, as well as manually checking high reads or abundant chromosomal regions with IGV 2.3.80. The trimmed sequencing samples were then processed using TopHat 2.1.1 (with Bowtie 2.2.9) and mapped to the mouse reference genome (NCBI reference assembly GRCm38.p4) and reference transcriptome (Gencode vM10) generating files in .bam format. We filtered reads such that uniquely mapped reads were processed for further analysis (Table 1). Processed .bam files were then quantified for each gene using Cufflinks 2.2.1 with gencode.vM10 genome annotation. Because reads only mapped to the $3^{\prime}$ untranslated region (UTR) of the gene, read counts were not normalized by length by the using the Cufflinks option, no-length-correction. Relative abundance for the $\mathrm{i}^{\text {th }}$ gene was determined by calculating transcripts per million (TPM) values as follows:

$$
T P M_{i}=10^{6} \times \frac{\alpha_{i}}{E_{j}\left[\alpha_{j}\right]}
$$

where $a_{j}$ is the Cufflinks reported relative abundance. Finally, TPM values were normalized to upper decile for each biological replicate and udTPM (upper decile TPM) were used for analysis (Glusman et al., 2013), to provide uniform processing for samples with varying sequencing depth and because of varying number of genes in the transcriptome and translatome.

\section{Antibodies and chemicals}

The peripherin and neurofilament 200 (NF200) antibodies used for immunohistochemistry were obtained from Sigma-Aldrich. Isolectin $\mathrm{B}_{4}$ $\left(\mathrm{IB}_{4}\right)$ conjugated to AlexaFluor-568 and secondary AlexaFluor antibodies were from Invitrogen. Calcitonin gene-related peptide (CGRP) antibody was purchased from Peninsula Laboratories International. The phospho- and total-eIF4E, 4EBP1, ERK, Akt, RagA, actin, S6, and GAPDH antibodies were obtained from Cell Signaling Technology. The phospho-eIF4E antibody used for immunohistochemistry was purchased from Abcam. AZD8055 was obtained from LC Laboratories, and eFT508 was provided by eFFECTOR under a Material Transfer Agreement agreement with the University of Texas at Dallas. For additional details on antibodies and chemicals used in this study, see Table 2.

\section{Thermal and mechanical testing}

Mice were housed on $12 \mathrm{~h}$ light-/dark cycles with lights on at 7:00 A.M. Mice had food and water available ad libitum. All behavioral experiments were performed between the hours of 9:00 A.M. and 6:00 P.M. Mice were randomized to groups from multiple cages to avoid using mice from experimental groups that were cohabitating. Sample size was estimated as $n<6$ using a power calculation with $80 \%$ power, expectations of $50 \%$ effect size, with $\alpha$ set to 0.05 . The number of animals used in each experiment was based on available animals of the appropriate sex and age but was at least $n=5$ for experiments. SD for power calculations was based on previously published data using similar models. Mice were habituated for $1 \mathrm{~h}$ to clear acrylic behavioral chambers before beginning the experiment. Mechanical paw withdrawal thresholds were measured using the up-down method (Chaplan et al., 1994) with calibrated Von Frey filaments (Stoelting). Thermal latency was measured using a hot/cold plate setting the temperature at $49^{\circ} \mathrm{C}, 50^{\circ} \mathrm{C}$, and $52^{\circ} \mathrm{C}$. For intrathecal injections, $10 \mu \mathrm{g}$ of AZD 8055 was injected in a volume of $5 \mu \mathrm{l}$ via a 30.5 -gauge needle. eFT508 for systemic injection was made up in 10\% DMSO and $90 \%$ polypropylene glycol in water and injected intraperitoneally in a volume of $100 \mu \mathrm{l}$ and adjusted based on the weight. Mice of both sexes were used in most experiments, and no significant differences between sexes were noted for drug or genotype in any experiments. The experimenter was blinded to the genotype of the mice and drug condition in all experiments.

\section{Conditioned place preference (CPP)}

We used a modified CPP procedure adapted from Yang et al. (2014). A homemade CPP box was constructed with three chambers with equal levels of dim illumination. The box was made with one black and one white end chamber connected by a striped chamber. On day 1 of testing (day 7 after the first injection of paclitaxel), each mouse was permitted to explore the striped and black (but not white) cham- 
Table 2. Antibodies and chemicals used in the study

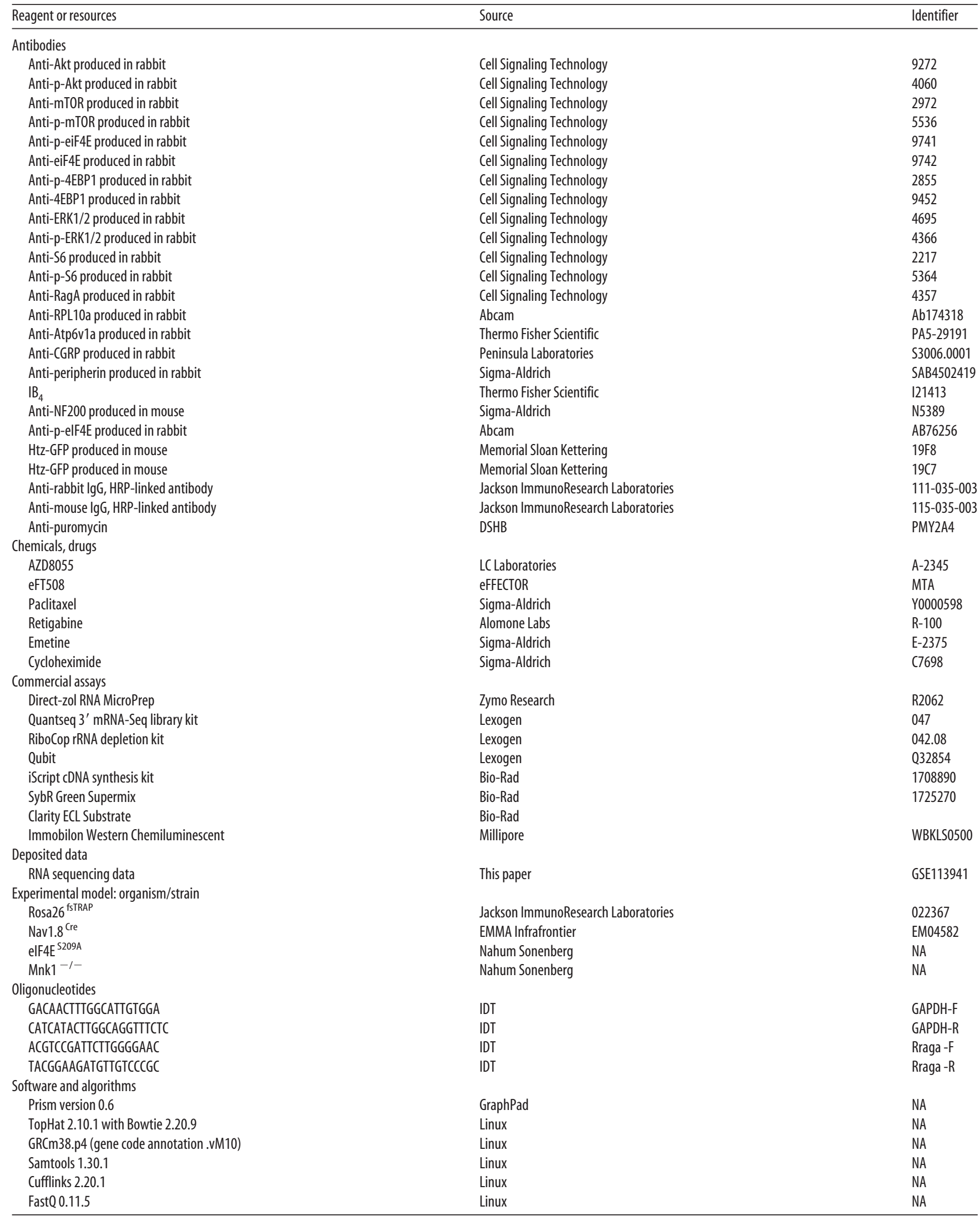

bers. Conditioning trials occurred on days 2-4. Each morning, $0.1 \mathrm{ml}$ of vehicle (saline) was injected intraperitoneally 10 min before confinement in the black chamber for $30 \mathrm{~min}$. Three hours later, the same mouse was injected with retigabine (Alomone Labs) $(10 \mathrm{mg} / \mathrm{kg}$ in 0.1 $\mathrm{ml}$ of saline). Ten minutes before confinement in the white chamber for $30 \mathrm{~min}$. On day 5, each mouse was placed in the striped chamber with unrestricted access to all chambers for $10 \mathrm{~min}$. Data are presented as the difference in time spent in the retigabine-paired (white) 
chamber minus time in the vehicle-paired (black) chamber during the drug-free day 5 test.

\section{Co-immunoprecipitation}

DRGs were transferred to ice-cold polysome buffer (20 mM HEPES, 12 $\mathrm{mm} \mathrm{MgCl}_{2}, 150 \mathrm{~mm} \mathrm{KCl}, 0.5 \mathrm{~mm}$ DTT, and protease inhibitor and homogenized using a Dounce homogenizer, and samples were centrifuged at $3000 \times g$ for $10 \mathrm{~min}$ to prepare the postnuclear fraction (S1). Then, $1 \%$ NP-40 and $30 \mathrm{~mm}$ DHPC were added S1 was centrifuged at 15,000 $\times g$ for $15 \mathrm{~min}$ to generate a postmitochondrial fraction (S20). A $200 \mu \mathrm{l} \mathrm{sample}$ of S20 was removed for use as input, and $800 \mu \mathrm{l}$ incubated with protein G-coated Dynabeads (Invitrogen) bound to anti-GFP antibodies (HtzGFP-19F7 and HtzGFP-19C8, Memorial Sloan Kettering Center) for $3 \mathrm{~h}$ at room temperature with end-over-end mixing. Anti-GFP beads were washed with high salt buffer (20 mM HEPES, $5 \mathrm{~mm} \mathrm{MgCl}_{2}, 350 \mathrm{~mm}$ $\mathrm{KCl}, 1 \% \mathrm{NP}-40$ ), and proteins were eluted from all samples using RIPA buffer and heated up to $55^{\circ} \mathrm{C}$ for $5 \mathrm{~min}$. The samples were then run on a $10 \%$ SDS-PAGE gel and immunoblot for L10a.

\section{$q R T-P C R$}

Lumbar DRGs were isolated from 4 male mice per genotype and flashfrozen on dry ice and stored at $-80^{\circ} \mathrm{C}$ until ready to be processed. Tissues were homogenized using a pestle and total RNA was extracted using RNAqueous Total RNA Isolation kits (Thermo Fisher Scientific). RNA was subsequently treated with TURBO DNase (Thermo Fisher Scientific) according to the manufacturer's instructions. RNA concentration was measured on a NanoDrop 2000 (Thermo Fisher Scientific). cDNA was synthesized using iScript Reverse Transcriptase (Bio-Rad). qRT-PCR was done using a Applied Biosystems Lightcycler 7500 real time PCR system using iTaq Universal SYBR Green Supermix (Bio-Rad) according to the manufacturer's instructions with 3 technical replicates per biological replicate (averages of the technical replicates per biological replicate are reported) using primers pairs: Gapdh forward 5'-GACAACTTTG GCATTGTGGA-3' and Gapdh reverse 5'-CATCATACTTGGCAGG TTTCTC-3', Rraga forward 5' -ACGTCCGATTCTTGGGGAAC-3' and Rraga reverse 5'-TACGGAAGATGTTGTCCCGC-3'. Primers were made by Integrated DNA Technologies. Data were analyzed as $2^{-\Delta \Delta \text { Cò }}$ and normalized as shown in Results.

\section{Measurement of protein synthesis}

Eight- to 12-week-old WT and eiF4E ${ }^{\text {S209A }}$ mice were injected with puromycin $(10 \mathrm{mg} / \mathrm{kg}$ i.p.), and $1 \mathrm{~h}$ later DRGs were collected and processed for Western blotting using anti-puromycin monoclonal antibody (PMY2A4, KeraFast). DRGs from mice injected with eFT508 (10 mg/kg i.p., injected $1 \mathrm{~h}$ before puromycin) or vehicle were processed in parallel and used as controls. Protein synthesis was determined by measuring total lane signal from 250 to $15 \mathrm{kDa}$ and subtracting unlabeled protein control. Signals were quantified using Image Lab (Bio-Rad).

\section{Immunohistochemistry}

Animals were anesthetized with isoflurane (4\%) and killed by decapitation and tissues were flash frozen in OCT on dry ice. Spinal cords were pressure ejected using chilled $1 \times$ PBS. Sections of DRG $(20 \mu \mathrm{m})$ were mounted onto SuperFrost Plus slides (Thermo Fisher Scientific) and fixed in ice-cold $10 \%$ formalin in $1 \times$ PBS for 45 min then subsequently washed 3 times for $5 \mathrm{~min}$ each in $1 \times$ PBS. Slides were then transferred to a solution for permeabilization made of $1 \times$ PBS with $0.2 \%$ Triton X-100 (Sigma-Aldrich). After $30 \mathrm{~min}$, slides were washed 3 times for 5 min each in $1 \times$ PBS. Tissues were blocked for at least $2 \mathrm{~h}$ in $1 \times$ PBS and $10 \%$ heat-inactivated normal goat serum. DRG slices were stained with peripherin and NF200, and immunoreactivity was visualized following $1 \mathrm{~h}$ incubation with goat anti-rabbit, goat anti-mouse, and goat anti-guinea pig AlexaFluor antibodies at room temperature. All immunohistochemical images are representations of samples taken from 3 animals per genotype. Images were taken using an Olympus FluoView 1200 confocal microscope. Analysis of images was done using ImageJ version 1.48 for Apple OSX (National Institutes of Health, Bethesda, MD).

\section{Acute dissociation of mouse DRG neurons}

Thirty mice were deeply anesthetized with isoflurane and the bilateral C4-5, T3-5, and L4-5 ganglia were surgically exposed and removed. The ganglia were placed in a flask containing trypsin $(6.25 \mu \mathrm{g} / \mathrm{ml}$, Hyclone $)$ and Type IA collagenase $(0.25 \mathrm{mg} / \mathrm{ml}$, Sigma-Aldrich $)$ in DMEM and shaken for $50 \mathrm{~min}$ in a heated $\left(37^{\circ} \mathrm{C}\right)$ bath. After the cells were washed and mechanically dispersed with a fire-polished Pasteur pipette, they were plated on poly-L-lysine-coated glass sheets and held in culture dishes with DMEM (10\% FBS) until use within $6 \mathrm{~h}$ after plating.

\section{Whole-cell patch recording of spontaneous and evoked action} potential in acutely dissociated mice DRG neurons

A previously described protocol was used (Li et al., 2017) for currentclamp recording. The internal solution contained $135 \mathrm{~mm} \mathrm{~K}$-gluconate, 5 mм KCl, 5 mм Mg-ATP, 0.5 mм Na 2 GTP, 5 mм HEPES, 2 mm $\mathrm{MgCl}_{2}$, 5 mM EGTA, and $0.5 \mathrm{~mm} \mathrm{CaCl}_{2}$ adjusted to $\mathrm{pH} 7.4$ with $\mathrm{KOH}$ and the bath ACSF solution. DRG neurons were held at $0 \mathrm{pA}$, and the action potential current threshold was evoked using a series of $300 \mathrm{~ms}$ depolarizing current injections in $10 \mathrm{pA}$ steps from $-50 \mathrm{pA}$. The current that induced the first action potential that was defined as $1 \times$ rheobase. Only neurons with a resting membrane potential of at least $-40 \mathrm{mV}$, stable baseline recordings, and evoked spikes that overshot $0 \mathrm{mV}$ were used for further experiments and analysis. The DRG neurons were then held at $0 \mathrm{pA}$ to record spontaneous action potential for $5 \mathrm{~min}$. The different times rheobase injections for $500 \mathrm{~ms}$ was applied to induce action potential spike-burst responses. Series resistance $\left(R_{s}\right)$ was compensated to $>70 \%$ for the recorded DRG neurons. All recordings were made at room temperature.

\section{Western blotting}

Male and female mice were used for all Western blotting experiments and were killed by decapitation following anesthesia, and tissues were flash frozen on dry ice. Frozen tissues were homogenized in lysis buffer $(50 \mathrm{~mm}$ Tris, $\mathrm{pH}$ 7.4, $150 \mathrm{~mm} \mathrm{NaCl}, 1 \mathrm{~mm}$ EDTA, $\mathrm{pH}$ 8.0, and 1\% Triton X-100) containing protease and phosphatase inhibitors (Sigma-Aldrich), and homogenized using a pestle. In vitro studies consisted of cultured primary DRG neurons from $\sim 4$-week-old mice. Mice were anesthetized with isoflurane and killed by decapitation. DRGs were dissected and placed in chilled HBSS (Invitrogen) until processed. DRGs were then digested in $1 \mathrm{mg} / \mathrm{ml}$ collagenase A (Roche) for $25 \mathrm{~min}$ at $37^{\circ} \mathrm{C}$ then subsequently digested in a $1: 1$ mixture of $1 \mathrm{mg} / \mathrm{ml}$ collagenase $\mathrm{D}$ and papain (Roche) for $20 \mathrm{~min}$ at $37^{\circ} \mathrm{C}$. DRGs were then triturated in a 1:1 mixture of $1 \mathrm{mg} / \mathrm{ml}$ trypsin inhibitor (Roche) and BSA (BioPharm Laboratories), then filtered through a $70 \mu \mathrm{m}$ cell strainer (Corning). Cells were pelleted, then resuspended in DMEM/F12 + Glutamax (Invitrogen) containing 10\% FBS (Invitrogen), $1 \%$ penicillin and streptomycin, and $3 \mu \mathrm{g} / \mathrm{ml} \mathrm{5-fluorouridine} \mathrm{with} 7 \mu \mathrm{g} / \mathrm{ml}$ uridine to inhibit mitosis of non-neuronal cells and distributed evenly in a 6-well plate coated with poly-D lysine (BD Biosciences). DRG neurons were maintained in a $37^{\circ} \mathrm{C}$ incubator containing $5 \% \mathrm{CO}_{2}$ with a media change every other day. On day 5, DRG neurons were treated as indicated in Results, and cells were rinsed with chilled $1 \times$ PBS and harvested in lysis buffer containing protease and phosphatase inhibitors (Sigma-Aldrich), and then sonicated for $10 \mathrm{~s}$. To clear debris, samples were centrifuged at 14,000 rpm for 15 $\min$ at $4^{\circ} \mathrm{C}$. Fifteen micrograms of protein was loaded into each well and separated by a $10 \%-12 \%$ SDS-PAGE gel. Proteins were transferred to a $0.45 \mu \mathrm{m}$ PVDF membrane (Millipore) at $25 \mathrm{~V}$ overnight at $4^{\circ} \mathrm{C}$. Subsequently, membranes were blocked with $5 \%$ non-fat dry milk (NFDM) in $1 \times$ Tris buffer solution containing Tween 20 (TTBS) for $3 \mathrm{~h}$. Membranes were washed in $1 \times$ TTBS 3 times for 5 min each, then incubated with primary antibody overnight at $4^{\circ} \mathrm{C}$. The following day, membranes were washed 3 times in $1 \times$ TTBS for 5 min each, then incubated with the corresponding secondary antibody at room temperature for $1 \mathrm{~h}$. Membranes were then washed with $1 \times$ TTBS 5 times for 5 min each. Signals were detected using Immobilon Western Chemiluminescent HRP substrate (Millipore). Bands were visualized using film (Kodak) or with a BioRad ChemiDoc Touch. Membranes were stripped using Restore Western Blot Stripping buffer (Thermo Fisher Scientific) and reprobed with another antibody. Analysis was performed using Image Lab (Bio-Rad).

\section{Motif analysis}

For each gene in the upregulated translation gene list, we created one $5^{\prime}$ UTR sequence per gene. For each gene, this was done by first extracting $5^{\prime}$ UTR sequences from all isoforms based on the Gencode annotation. 
A

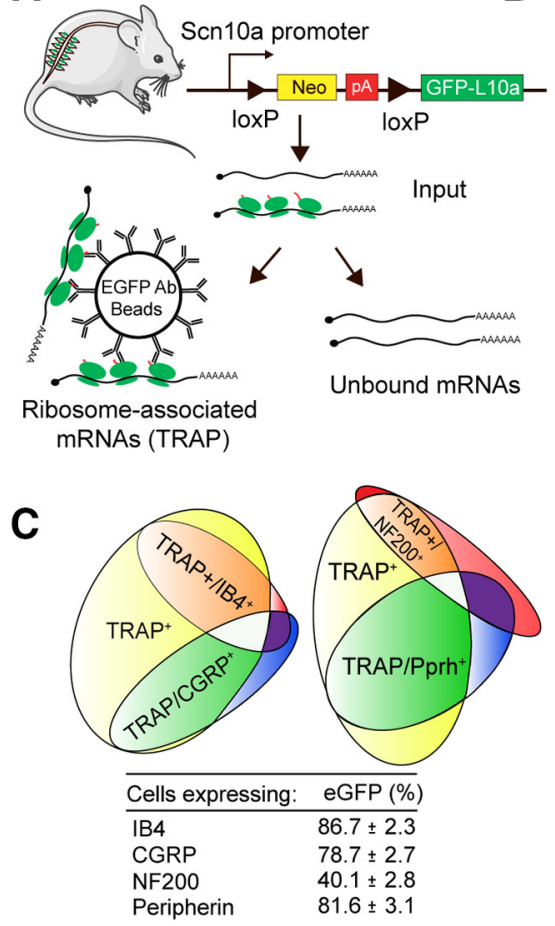

B
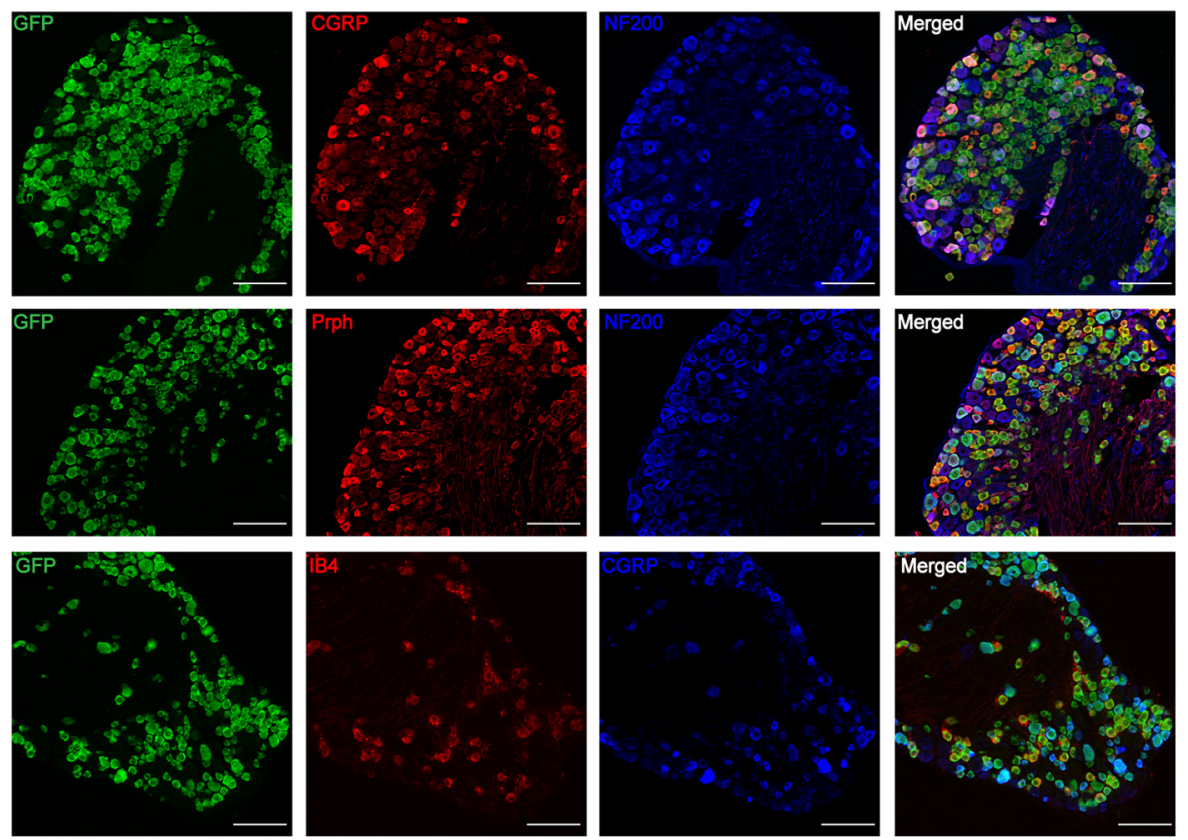

Figure 1. Expression of the fused EGFP-L10a protein in Nav1.8-positive nociceptors. $\boldsymbol{A}$, Schematic representation of TRAP shows isolation of translating ribosomes (IP) from input using anti-eGFP-coated beads. B, C, Immunostaining for CGRP, IB4, NF200, and TRPV1 on L4-DRG sections from Nav1.8 ${ }^{\text {cre } / T R A P ~ f l o x e d ~}$ mice. A total of 9528 , 8258, and 8526 neurons were counted for CGRP, NF200, and Prph staining, respectively; $n=3$ mice/group. Scale bars, $100 \mu \mathrm{m}$. Figure 1-1 (available at https://doi.org/10.1523/JNEUROSCI.2661-18.2018.f1-1) shows additional validation of TRAP mice.

Isoforms with $5^{\prime}$ UTRs $<20$ bases, or with sequence that is part of an ORF in another isoform were discarded. The remaining isoforms were collapsed into a single sequence in order of their location in the genome, with overlapping regions present exactly once in the sequence. Based on the set of $5^{\prime}$ UTRs, the motif finding tool MEME (https://www.ncbi. nlm.nih.gov/pubmed/19458158) was used to identify motifs of length $6-12$ bps, having at least 10 instances in our set of sequences. The background sequence set was simulated by MEME based on a 0 th order model of nucleotide composition based on the $5^{\prime}$ UTRs to avoid motifs identified as a result of nucleotide compositional biases, the 3 statistically significantly enriched motifs identified are shown, along with the genes they occur in, as well as the $e$ values (expected number of instances for the motif, statistical significance threshold for $e$ value used is 0.01 ).

\section{Statistics}

All data are represented as mean \pm SEM. All analysis was done using GraphPad Prism 6 version 6.0 for Mac OS X. For qPCR and Western blot experiments, significant outliers ( $>2$ SD from the mean) were removed using one-sided Dixon's test at a significance $(p<0.05)$. Single comparisons were performed using Student's $t$ test, and multiple comparisons were performed using a one-way ANOVA with post hoc tests for betweengroup comparisons. For behavioral experiments, two-way ANOVA (time $\times$ treatment) was used to measure effects across time between different groups. If significant effects were found by ANOVA, post hoc analyses were performed. Multiple comparisons between/within groups were performed using Bonferroni correction. Statistical results can be found in the figure legends. Electrophysiological recordings were analyzed using an unpaired $t$ test. DRG intracellular current injection neurophysiology data were analyzed with two-way ANOVA (treatment $\times$ rheobase times) followed by Bonferroni post hoc tests (corrected $p<$ $0.05) . p<0.05$ was considered statistically significant.

Statistics for RNA sequencing. Differential expression analysis was performed using MATLAB scripts. Briefly, TPM values were normalized to their 90th percentile to generate udTPM, and the probability density function of the udTPM was used to set the threshold value for further analysis. Genes showing consistent expression above the set threshold across biological replicates were then used to generate lists of differential expressed genes. Standard $t$ test was first performed assuming unequal variances between experimental groups generating $p$ values for each gene as follows. A $q$ value for the $\mathrm{i}^{\text {th }}$ test was then calculated using BenjaminiHochberg correction for multiple comparisons as follows:

$$
\text { Qvalue }_{i}=\frac{\text { pvalue }_{i} \times N}{\text { rank }_{\text {pvalue }_{i}}}
$$

where $N$ is the number of tests.

Finally, the cumulative density function of the fold change was plotted and used to set the fold change for the input and TRAP fraction. Gene set enrichment analysis was performed with Enrichr (Kuleshov et al., 2016) using the Gene Ontology molecular function (2015) and biological process (2015) and the Reactome (2015) libraries.

Data and software availability. Raw RNA sequencing data are available through GEO number GSE113941. All raw data and code are available upon request.

\section{Results}

To generate nociceptor-enriched ribosome-tagged mice, Nav1. $8^{\text {cre }}$ mice were crossed with Rosa $26^{\text {fs-TRAP }}$ (Zhou et al., 2013), to express eGFP fused to the ribosomal L10a protein in Nav1.8positive neurons (Fig. 1A). To ensure the specificity of our approach, we characterized expression of the transgene in the DRG. We found that eGFP-L10a-positive neurons primarily colocalized with small-diameter peripherin-positive neurons ( $81 \pm$ $3.1 \%$ ), whereas a smaller proportion of eGFP-labeled neurons coexpressed NF200, a marker of large-diameter neurons (40.1 \pm $2.8 \%$ ) (Fig. $1 B, C$ ). The percentage of eGFP-L10a-positive neurons was equally distributed between nonpeptidergic (86.7 \pm $2.3 \%$ ) and peptidergic neurons $(78.7 \pm 2.7 \%$ ) (Fig. 1C). We did 
A

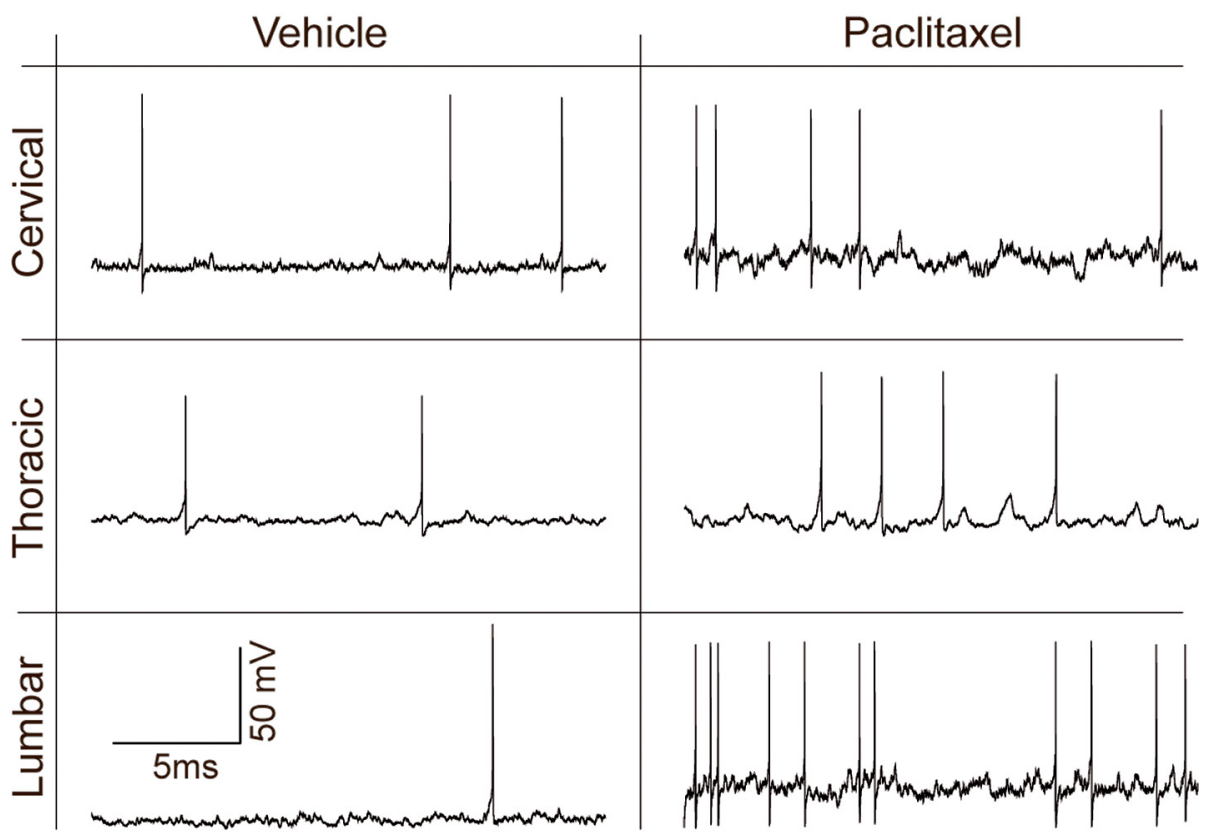

B
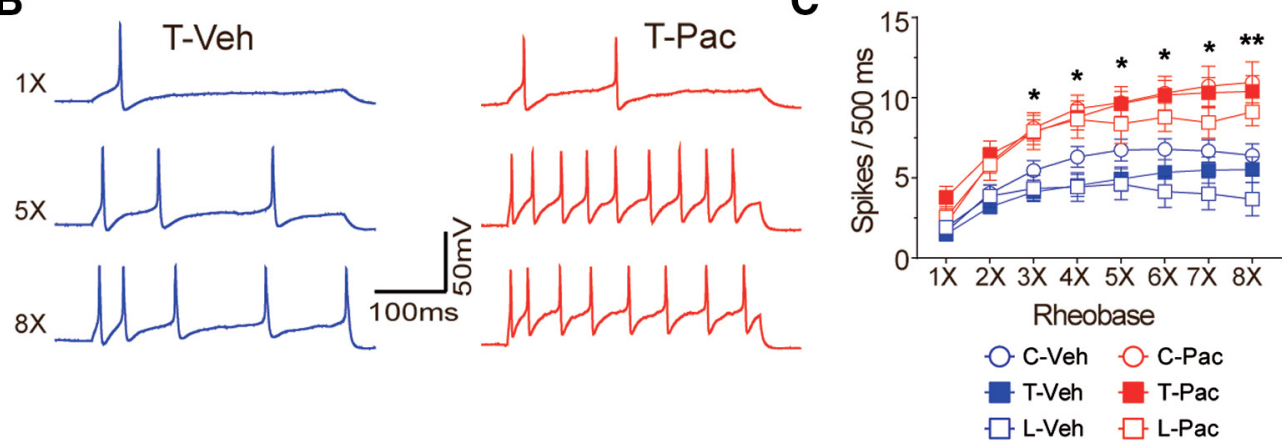

Figure 2. Paclitaxel treatment elicits increased excitability in cervical, thoracic and lumbar mouse DRG neurons. $A$, DRG neurons from mice treated with paclitaxel show hyper-amplitude of cell membrane oscillation. Left column shows representative recordings of the spontaneous activity (SA) observed in vehicle-treated mice DRG neurons from cervical (top trace), thoracic (middle trace) and lumbar (bottom trace) level. Right column shows representative recordings of the SA observed in DRG neurons from paclitaxel-treated mice at different vertebral levels. Neurophysiological activity was recorded from $247 \mathrm{small}$ diameter $(<22 \mu \mathrm{m})$ neurons at day 10 after paclitaxel treatment including 129 cells from vehicle-treated control mice $(49,43$ and 37 cells for cervical, thoracic and lumbar respectively) and 118 cells from paclitaxel-treated mice ( 41,37 and 40 cells for cervical, thoracic and lumbar respectively). B, C, Representative action potential responses evoked at $1 \times$, $5 \times, 8 \times$ rheobase in DRG neurons from vehicle and paclitaxel-treated mice. DRG neurons from paclitaxel-treated animals showed that the mean number of action potentials evoked at $3 \times$ to $8 \times$ rheobase was significantly higher. (Two-Way ANOVA: $F_{(1,429)}=56,51, p<0.0001$ and post-hoc Bonferroni test ${ }^{*} p<0.05$ at $3 \times$ and $4 \times{ }^{* *} p<0.01$ at $5 \times, 6 \times, 7 \times$ and $8 \times$.

Table 3. Sex of animals by genotype in behavioral experiments in this study

\begin{tabular}{|c|c|c|c|c|c|c|}
\hline Test & WT males & WT females & elF4E ${ }^{5209 A}$ males & elF4E $E^{5209 A}$ females & $M N K 1^{-I-}$ males & MNK1 ${ }^{-l-}$ memales \\
\hline von Frey (Fig. 3C) & 4 & 2 & 2 & 5 & - & - \\
\hline von Frey (Fig. 3D) & 6 & - & 6 & - & - & - \\
\hline Hot plate (Fig. $7 E$ ) & 2 & 4 & 3 & 3 & - & - \\
\hline CPP (Fig. 7F) & 10 & 5 & 8 & 7 & - & - \\
\hline von Frey (Fig. $4 B$ ) & 5 & 7 & - & - & - & - \\
\hline Hot plate (Fig. 4C) & 5 & 7 & - & - & - & - \\
\hline von Frey (Fig. 10E) & - & 6 & - & - & 2 & 3 \\
\hline
\end{tabular}

not observe eGFP-L10a expression in non-neuronal cells in the DRG. Thus, this approach specifically labels sensory neurons, including a substantial subset of neurons that are involved in nociception. We refer to these mice as Nav1.8-TRAP mice because they express tagged ribosomes specifically in the Nav1.8 population of DRG neurons.

We then used Nav1.8-TRAP mice to preliminarily characterize the translatome of DRG neurons that express Nav1.8 using
mRNAs isolated with immunoprecipitation of translating ribosomes (Heiman et al., 2014). First, we determined that immunoprecipitation of eGFP-L10a from DRGs of control and Nav1.8-TRAP mouse strains yielded a specific immunoprecipitation of eGFP-L10a using eGFP antibodies (Fig. 1-1 A, available at https:/doi.org/10.1523/JNEUROSCI.2661-18.2018.f1-1). We also used immunoprecipitation combined with qRT-PCR for several mRNAs that are known to be enriched in nociceptors (Corder et al., 
A

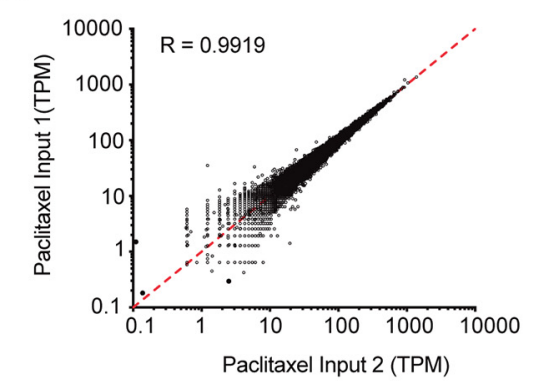

C

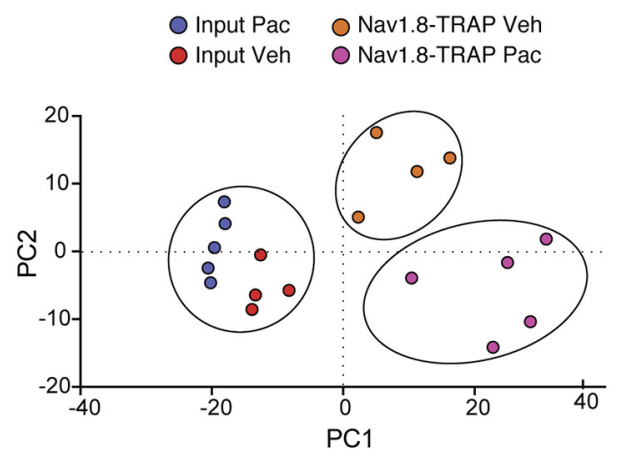

B
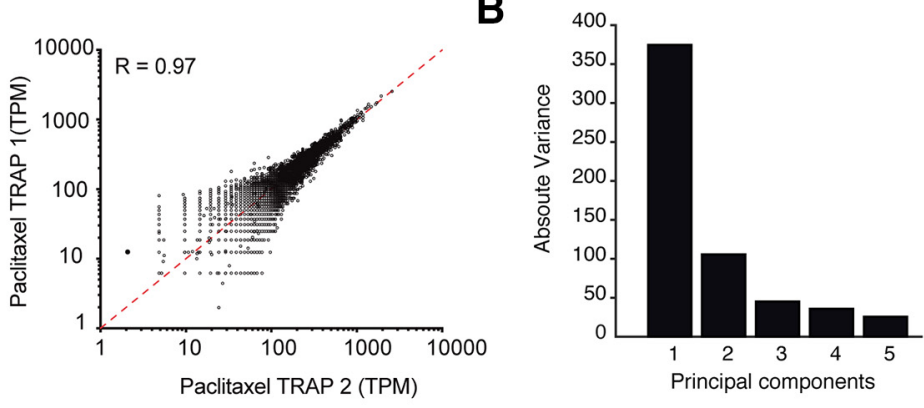

D

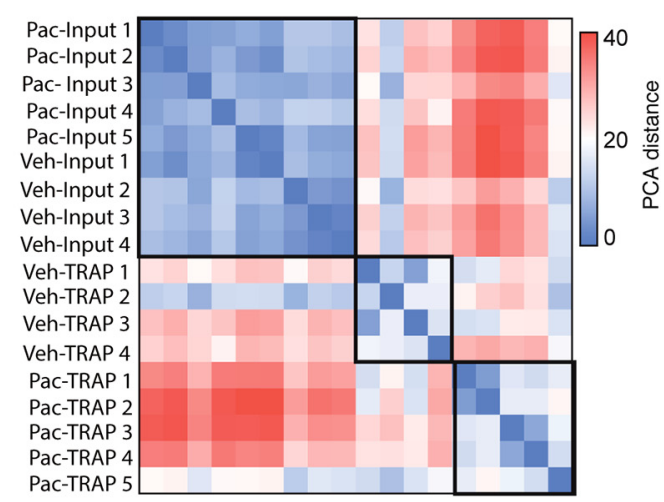

Figure 3. Principal component analysis (PCA) reveals specific transcriptomic and translatomic signatures of CIPN. $A$, Linear correlation plot shows high correlation coefficient between biological replicates for the TRAP and input fractions. $\boldsymbol{B}$, Absolute variances calculated for the first fifth principal components. $C$, PCA shows that the first principal component (PC1) differentiates between input (Transcriptome) and TRAP (Translatome). D, Heatmap showing the PCA distances between each biological replicate. Related to Figure 1.

2017) to demonstrate integrity of the immunoprecipitationmRNA complex (Fig. 1-1B-D, available at https://doi.org/10. 1523/JNEUROSCI.2661-18.2018.f1-1). These experiments demonstrate that the Nav1.8-TRAP approach can be used to tag ribosomes and capture mRNAs from nociceptive DRG neurons.

One outcome of these characterization experiments was the realization that a large amount of starting material is required to successfully isolate ribosome-associated mRNAs from Nav1.8TRAP cells. We determined that DRGs from cervical, thoracic, and lumbar levels from 4 animals were minimally required for a single biological replicate for accurate TRAP-seq in this tissue. Because a goal of our experiments was to assess the nociceptor translatome using RNA sequencing (Nav1.8-TRAP-seq) in neuropathic pain, this prompted us to use a neuropathy model where all DRGs are affected by the treatment. Paclitaxel-induced CIPN is a common form of neuropathic pain with devastating consequences for patients (Ma et al., 2018). The common descriptions of this form of CIPN include a "stocking and glove" distribution (Seretny et al., 2014; Ma et al., 2018), questioning whether pathology is found at all DRG levels from the drug treatment. Given that this would have obvious consequences for our experimental approach, we sought to assess whether electrophysiological changes were found at all DRG levels in mice treated with paclitaxel. We treated Nav1.8-TRAP mice with the commonly used chemotherapeutic agent, paclitaxel $(4 \mathrm{mg} / \mathrm{kg})$ every other day, intraperitoneally, for a total of $8 \mathrm{~d}$. We isolated cervical, thoracic, and lumbar DRGs on day 10 after initiation of treatment from mice treated with vehicle or paclitaxel and performed patchclamp electrophysiology. Paclitaxel treatment caused spontaneous activity and increased nociceptor excitability (Fig. $2 A-C$ ) at all DRG levels.

Having determined that paclitaxel affects nociceptors in all DRGs, we pooled samples from 4 mice ( 2 male and 2 female) per treatment, per biological replicate for high-throughput sequencing. Subsequent behavioral and biochemical experiments were performed in males and females (Table 3). On day 10 after the start of paclitaxel or vehicle treatment, we collected eGFP-L10a immunoprecipitations from Nav1.8-TRAP mice for RNA sequencing. From all biological replicates, we sequenced input mRNA, equivalent to the DRG transcriptome, and TRAP mRNAs associated with translating ribosomes in the Nav1.8 subset of DRG neurons (TRAP-seq). This approach allowed us to make comparisons of transcriptional and translational changes in response to paclitaxel in a cell type-specific fashion. We observed strong correlation coefficients between biological replicates for the input and TRAP samples demonstrating high reproducibility across experiments (Fig. $3 A$ ). Principal component analysis did not distinguish between treatment conditions in input samples, whereas robust differences were found in the TRAP-seq samples, suggesting that the key differences driving neuropathic pain generated by paclitaxel are happening at the translational level in Nav1.8-positive neurons (Fig. 3B-D).

As an additional control for the specificity of our approach, we analyzed a subset of genes that are known to be enriched in different cell populations in the DRG. This analysis demonstrated that TRAP-seq allowed the isolation of translating mRNAs in a cell type-specific manner. Neuronal mRNAs, such as Calca $(\mathrm{CGRP} \alpha), \mathrm{Calcb}(\mathrm{CGRP} \beta)$, or $\operatorname{Scn} 10 a(\mathrm{Nav1} 1.8)$, were enriched in TRAP fractions, whereas glial markers (Aldh1l1, Gfap) and endothelial specific genes (Cldn5, Esam) were depleted. (Fig. 4A). For subsequent genomewide analysis, gene expression values (TPM) were normalized to the 90th percentile for each biological replicate and the empirical probability density function of the normalized expression level upper decile TPM (udTPM) was plotted for the input and TRAP fractions (Fig. 4B). The probability density function displayed 2 peaks (Fig. $4 B$ ), and the inflection point 
A

B

Input

Nav1.8-TRAP
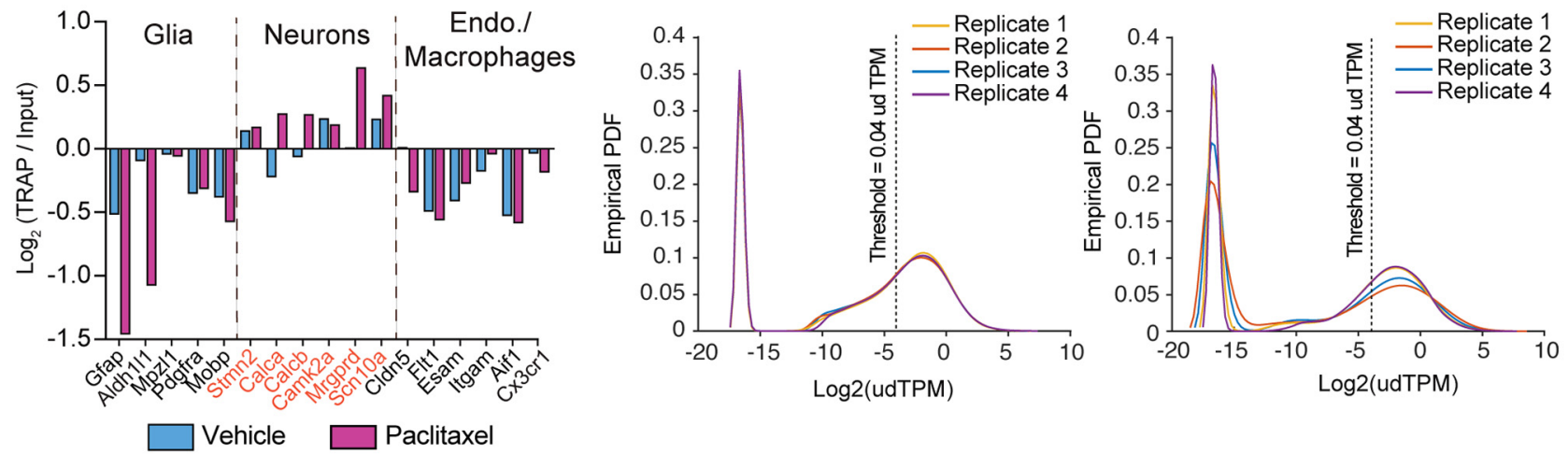

C

D

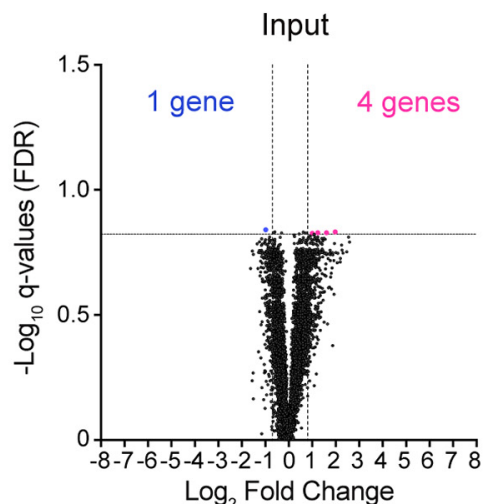

Nav1.8-TRAP
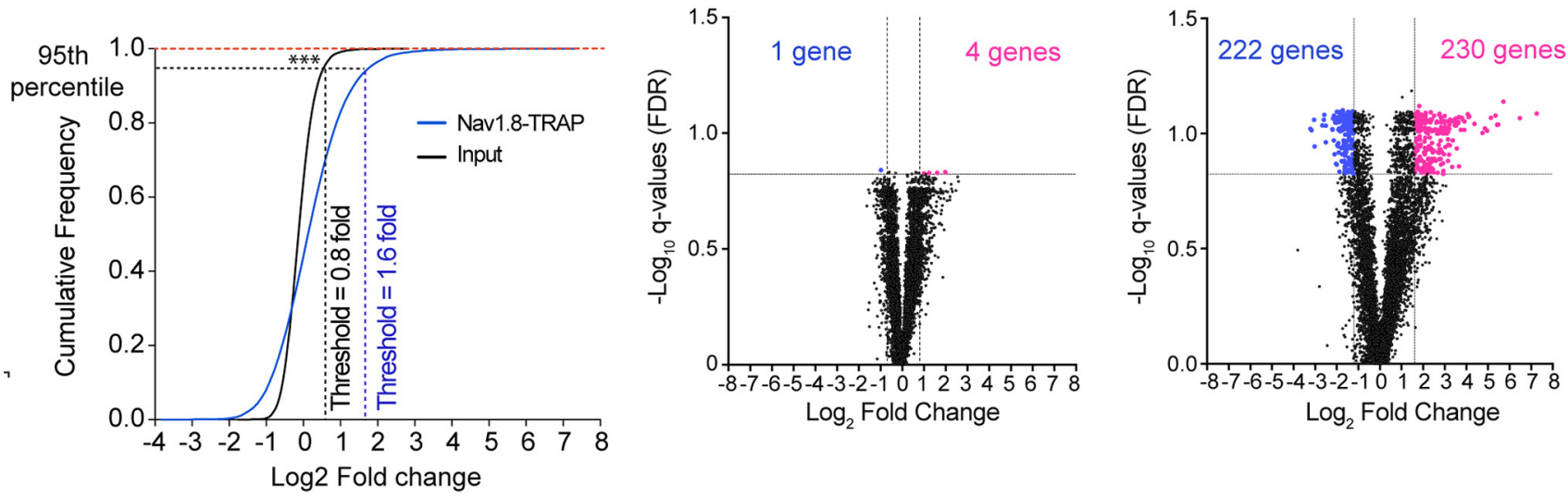

$\mathbf{E}$

$\mathbf{F}$

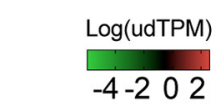

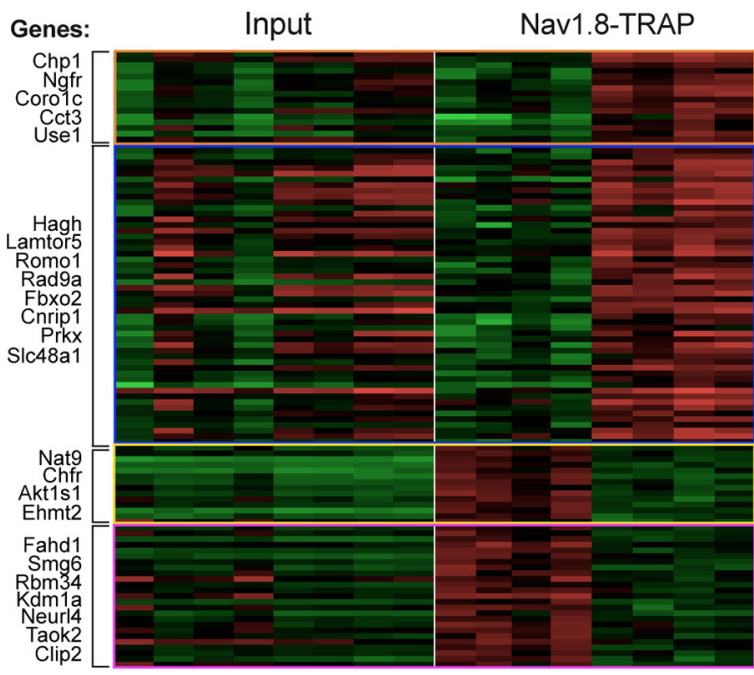

C1

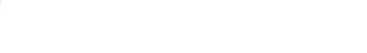

$-\log _{10}$ adjusted p-values
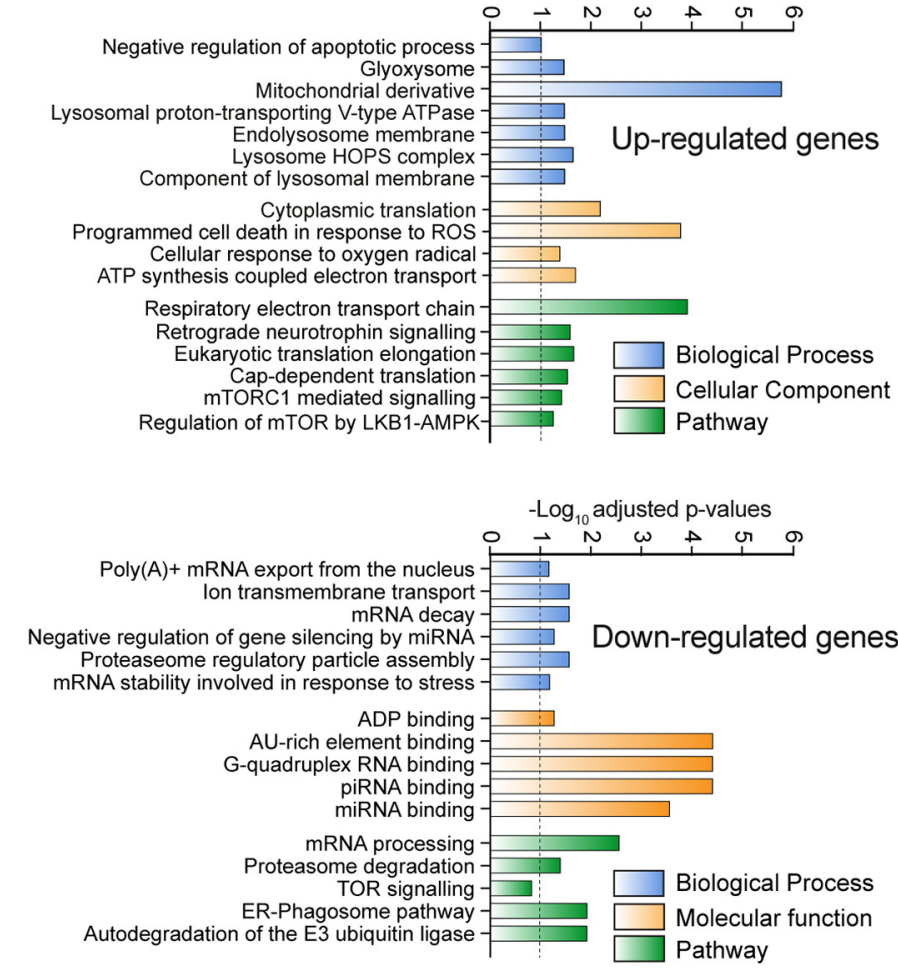

Figure 4. TRAP-seq identifies differentially translated mRNAs in Nav1.8-positive nociceptors. A, DRG-TRAP-seq is enriched in neuronal markers, such as Calca (CGRP) or Camk2a, whereas glial (Aldh111, Gfap), endothelial (Cldn5, Fit1), and microglial ( $(x \mathrm{Cr} 3$, Aif1) markers are depleted. $\boldsymbol{B}$, The probability density function of the upper decile udTPM distribution for the input and TRAP fraction where the inflection point was used to set the expression threshold for further analysis. $C$, The threshold effect size is set using the cumulative distribution of the log 2 fold change for the input and TRAP fractions showing a significant shift toward high fold change in the TRAP fraction: ${ }^{* * *} p<0.0001,1-p<0.001$ (Kolmogorov-Smirnov). Related to Figure 1.D, Volcano plot reveals 4 genes upregulated and 1 downregulated in the transcriptome, whereas more widespread changes are observed in the translatome (TRAP). $\boldsymbol{E}$, Heatmap shows the fold change of (Figure legend continues.) 
was used to set the threshold expression values according to the sequencing depth. After further filtering, based on consistent expression among biological replicates, we included a total of 8270 genes in the final analysis. We then plotted the cumulative frequency distribution as a function of the log twofold change for each of these genes in vehicle- versus paclitaxel-treated biological replicates, and the 95th percentile was used to set the threshold fold change values for the input and TRAP fractions (Fig. 4C). Input transcriptome analysis revealed that only 4 genes were upregulated (Dpep2, Car3, Iah1, and Arhgef4) and 1 was downregulated $(P l c b 3)$ in the DRG by paclitaxel treatment when looking at the whole transcriptome of the DRG at day 10 after treatment(Fig. 4D; Fig. 4-1, available at https://doi.org/10.1523/ JNEUROSCI.2661-18.2018.f4-1). This finding suggests that, at this time point, there are relatively few transcription changes induced by paclitaxel treatment in the whole DRG. In stark contrast, and consistent with the notion that transcriptional and translational changes are frequently decoupled (Liu et al., 2016), which is shown graphically for our dataset in Figure $4 E$, we detected 230 genes upregulated (Fig. 4D,E; Fig. 4-2, available at https://doi.org/10.1523/JNEUROSCI.2661-18.2018.f4-2) and 222 downregulated (Fig. 4D,E; Fig. 4-3, available at https://doi. org/10.1523/JNEUROSCI.2661-18.2018.f4-3) by paclitaxel treatment in the TRAP-seq dataset. These differences between transcriptome and translatome demonstrate the utility of the TRAP approach for identifying changes in gene expression that cannot be accounted for with traditional transcriptomic analysis.

We then investigated what classes of genes were significantly enriched in the upregulated and downregulated mRNA TRAPseq dataset using the EnrichR tool (Kuleshov et al., 2016). First, validating that this approach can identify pathological changes in nociceptors that have already been linked to CIPN (Bennett et al., 2014), reactive oxygen species, and mitochondrial dysregulation signatures were significantly enriched in the paclitaxel-treated TRAP-seq dataset. Likewise, several translationally upregulated mRNAs found in our dataset have already been identified in the CIPN literature using independent methods, such as caspase 6 (Berta et al., 2017). We also found a significant enrichment of genes involved in the regulation of cap-dependent translation, the lysosomal complex, and mTORC1 signaling (Fig. $4 F$ ).

Combining this dataset with single-cell RNA sequencing from existing data sources (Usoskin et al., 2015; Hu et al., 2016) allowed us to infer translation efficiencies (TEs) for all mRNAs translated in Nav1.8 neurons creating a rich resource for understanding steady-state translation of mRNAs expressed in nociceptors (https://www.utdallas.edu/bbs/painneurosciencelab/ sensoryomics/cipntrap/browse.html). We strictly limited ourselves to calculating TEs for mRNAs that are found in the Nav1.8 population of neurons as defined by single-cell RNA sequencing because high expression in other cell types would bias TEs toward less translation efficiency because our translating ribosome associated mRNA sequencing is restricted to the Nav1.8 population (Fig. 5A). We examined families of genes for any

\footnotetext{
(Figure legend continued.) differentially expressed genes in each biological replicate of vehicle- and paclitaxel-treated animals (TRAP and input fractions). $\boldsymbol{F}$, EnrichR analysis of the upregulated genes in paclitaxel TRAP-seq samples. Figure 4-1 (available at https://doi.org/ 10.1523/JNEUROSCI.2661-18.2018.f4-1) shows differentially expressed genes in the transcriptome after CIPN. Figure 4-2 (available at https://doi.org/10.1523/JNEUROSCI.266118.2018.f4-2) shows genes differentially expressed upregulated in the (IPN TRAP-seq dataset. Figure 4-3 (available at https://doi.org/10.1523/JNEUROSCI.2661-18.2018.f4-3) shows downregulated genes in the CIPN TRAP-seq dataset.
}

systematic differences in TEs for mRNAs expressed in Nav1.8positive neurons (e.g., ion channels, G-protein coupled receptors, and kinases). Interestingly, we observed that ion channels and GPCRs tended to show higher TEs compared with other families, such as kinases, RNA-binding proteins, or transcription factors. When we looked at specific genes in each family we found a clear increase in TE for Trpv1 (Fig. 5B), which has been shown to be upregulated after paclitaxel (Li et al., 2015) and translationally upregulated by $\mathrm{p} 38$ signaling in the DRG in an inflammatory pain model (Ji et al., 2002). Also, we observed a decrease in TE for Chrna6 associated with an increase in TE for P2rx2 after CIPN (Fig. $5 B$ ). Interestingly, previous studies have demonstrated that Chrna6 is a negative regulator of P2rx2 and that Chrna6 mutations that decrease this functional inhibition are correlated with chronic pain (Wieskopf et al., 2015). Therefore, decreased Chrna6 expression in CIPN may sensitize nociceptors to ATP released from a variety of different sources via enhanced function of $\mathrm{P} 2 \mathrm{X} 2 / \mathrm{P} 2 \mathrm{X} 3$ receptors.

Having established alterations in the nociceptor translatome with paclitaxel treatment, we then sought to examine whether there were motifs in the $5^{\prime}$ UTRs of mRNAs upregulated after CIPN. We found a clear enrichment in 3 motifs. Most prominent among them was a TOP-like element (Fig. 6). TOP elements are found in the 5' UTRs of mRNAs that are regulated by mTORC1 signaling (Thoreen et al., 2012). This finding is consistent with our gene ontology results (Fig. $4 F$ ) and reinforces the concept that mTORC1-regulated mRNA translation is a critical component of neuronal plasticity after paclitaxel treatment. We also found an enrichment in an AG-rich motif with unknown function and a G-quartet-like motif (Fig. 6). The G-quartet motif suggests translation control by the RNA helicase, eIF4A (Wolfe et al., 2014). Interestingly, a specific eIF4A isoform, eIF4a3, was found as being highly translated after CIPN (Fig. 4-2, available at https://doi.org/10.1523/JNEUROSCI.2661-18.2018.f4-2); and Mtor, which was also translationally increased by CIPN (Fig. 7A), contains a G-quartet-like motif in its 5' UTR. This suggests that the RNA helicase eIF4A could regulate the translation of the Mtor mRNA.

We then turned to biochemical methods to validate selected TRAP-seq results. We confirmed changes in steady-state protein levels with paclitaxel treatment for proteins, including mTOR (Fig. 7B) and Esyt1 (Fig. 7-1, available at https://doi.org/10.1523/ JNEUROSCI.2661-18.2018.f7-1). The concordance between measurements indicates that TRAP-seq can reliably predict increases in protein expression in DRG after CIPN. Based on increased mTOR protein levels, we also examined downstream and associated targets of $\mathrm{mTOR}$ where we noted increases in $\mathrm{p}-4 \mathrm{EBP} 1$ expression (Fig. $7 B$ ), but no differences in phosphorylation or total protein levels for ERK, AKT, or, surprisingly, ribosomal protein S6 (Fig. 7-2, available at https://doi.org/10.1523/JNEUROSCI. 2661-18.2018.f7-2). We also found that eIF4E phosphorylation was increased with paclitaxel treatment (Fig. $7 B$ ). These findings suggest a selective increase in signaling via a subset of proteins that control translation of genes involved in neuronal plasticity (Gkogkas et al., 2014; Moy et al., 2017). To test this hypothesis, we asked whether mTOR inhibition or genetic loss of the phosphorylation site for $\mathrm{MNK}$ on the cap-binding protein eIF4E $\left(\right.$ eIF4E ${ }^{\text {S209A }}$ ) would impair CIPN.

We used the ATP competitive mTORC1/2 inhibitor AZD8055 to examine the influence of mTOR inhibition on paclitaxelinduced pain. While a robust reduction in mechanical hypersensitivity occurred with the first intrathecal injection of AZD8055, the magnitude of this effect was decreased upon subsequent 
A
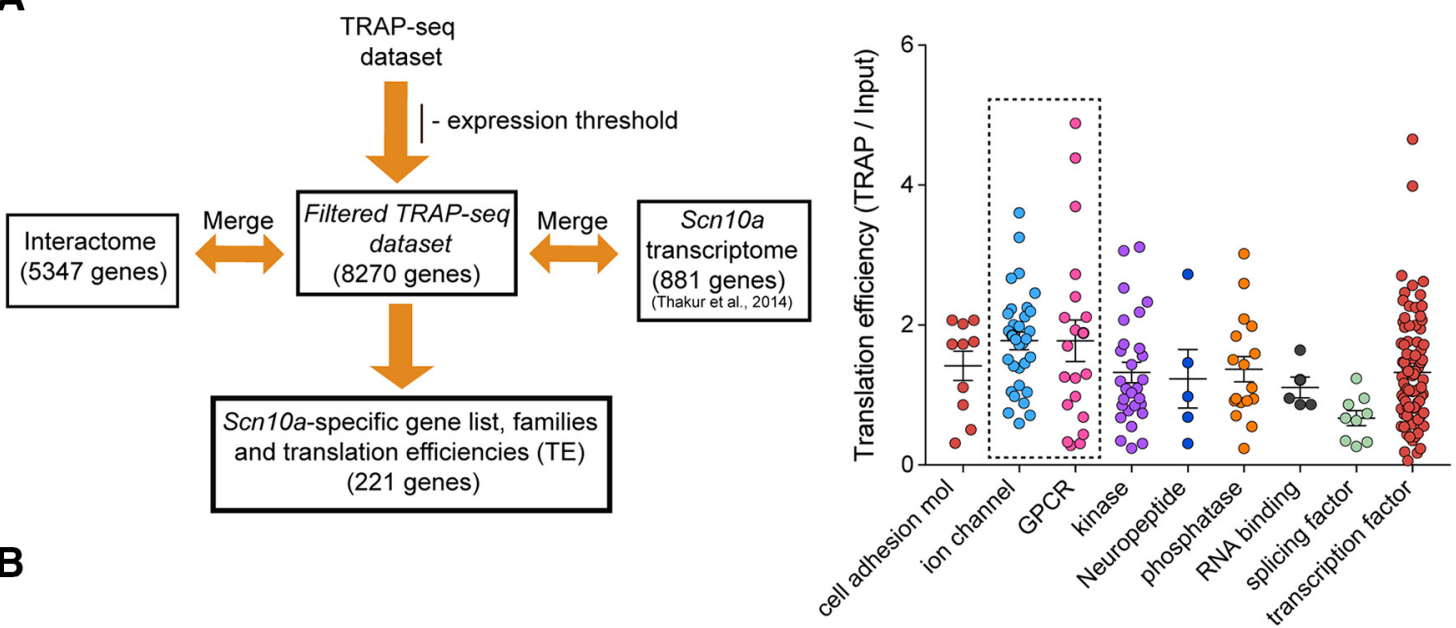

B
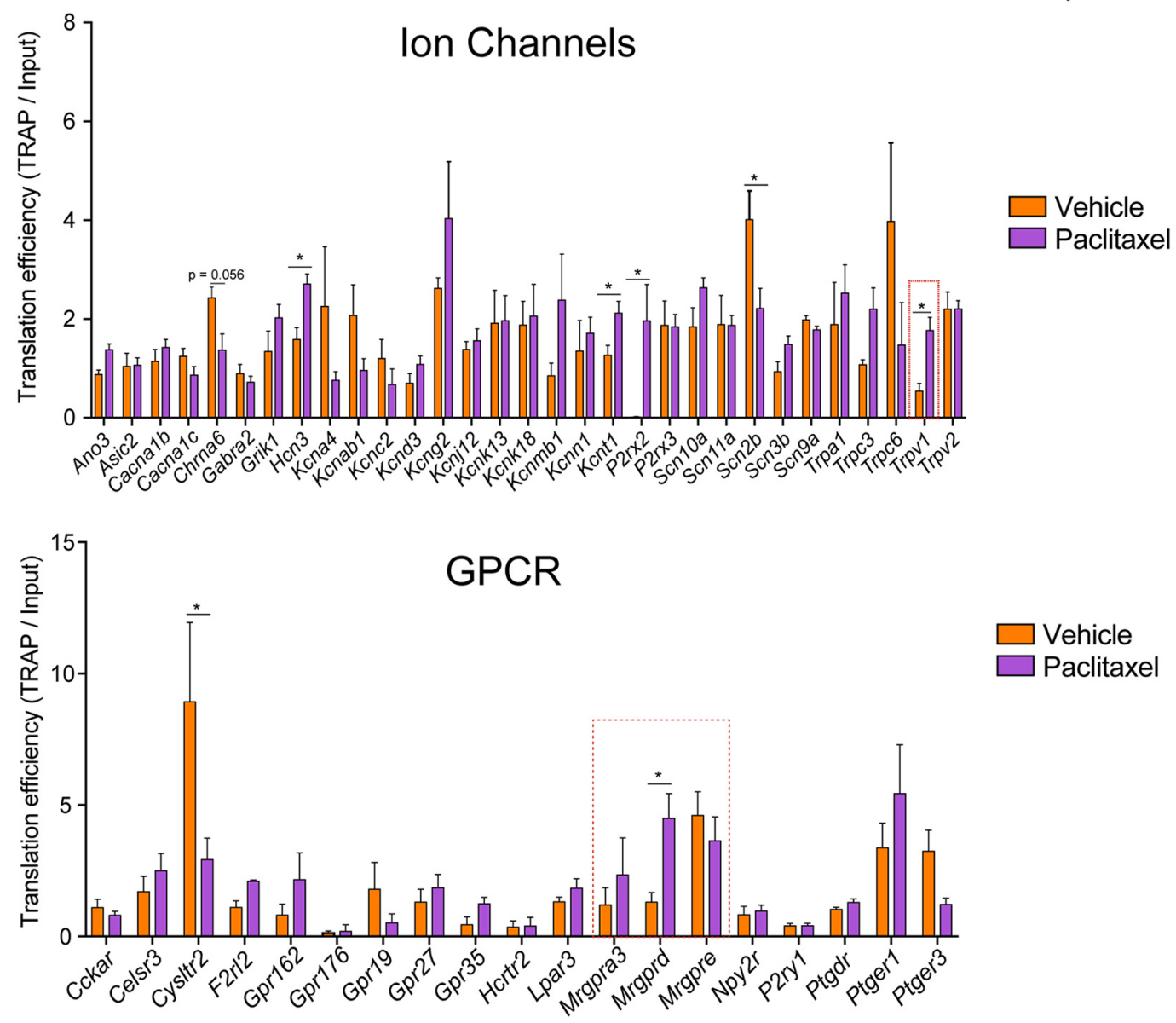

Figure 5. Translation efficiencies of $S \mathrm{Cn} 10 \mathrm{a}$-enriched genes show reliable changes in expression level for GPCR and ion channels. $A$, The list of genes in the TRAP-seq dataset is first filtered based on expression level (Fig. 4), and the remaining 8270 genes were used for further analysis. Separately, we used available RNA sequencing dataset from magnetic sorted cell to generate a list of 881 genes expressed in Scn10a-positive neurons as well as an interactome dataset built in the laboratory that contains a total of 5347 genes. A final list of 221 of $S c n 10$ a-enriched genes was used to calculate the respective TEs in vehicle or paclitaxel conditions. The Interactome analysis shows higher translation efficiencies for genes encoding ion channels and GPCR. $\boldsymbol{B}$, Gene $\times$ gene analysis reveals that multiple channels have high TE after CIPN, such as P2rx2 (multiple $t$ tests with correction for multiple comparisons: ${ }^{*} p=0.039, q<0.1$ ) or TRPV1 (multiple $t$ tests with correction for multiple comparisons: ${ }^{*} p=0.0059, q<0.1$ ), whereas Mrgrpd is the only GPCR showing a significant increase in TE after CIPN (multiple $t$ tests with correction for multiple comparisons: ${ }^{*} p=0.0049$, $q<0.1)$.

treatments (Fig. 7C). We attribute this rapid onset, tolerance-like effect to the known phenomena of feedback signaling in the mTOR pathway (Melemedjian et al., 2013; Soares et al., 2015). Although we see clear signs of augmented mTORC1 signaling in this CIPN model, this limited efficacy with repeated dosing makes mTORC1 a less attractive target for therapeutic intervention in CIPN.

We then turned to a genetic approach to examine the possibility of targeting MNK-eIF4E signaling in CIPN. Our previous work on this target suggests a key role in certain types of pain 


\section{Motif model Name (e value) Gene 5'UTRs with motif instance(s)}

Adamts8, Arl6, Atp5j2, Btbd2, Chchd10, Cisd2,
Dlg2, Gm20721, Gpr75, H2-T23, Igtp, Lcmt1,
Mok, Mpp4, Nme2, Prg4, Ptp4a3, Rho, Rnase4,
$\begin{gathered}\text { TOP-like motif } \\ \left(\text { e-score: } 8 \times 10^{-16}\right)\end{gathered}$

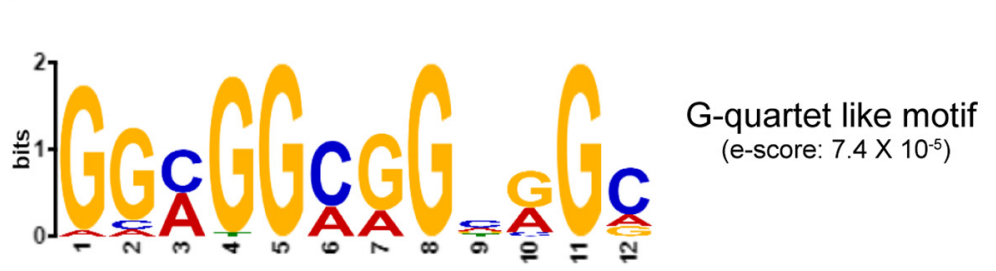

Acap3, Amd1, Amer2, Arl3, Bc/3, C77080, Cnih4, Dnajb1,

Dolk, Elk4, Fabp7, Fads3, Fsd1, Gmppa, Gpr75, Ift122, Igtp,

Mmd, Mtor, Pcbd2, Pgrmc2, Ppp1ca, Prdx5, Prkrir, Ptprf,

Pxdc1, Sec14l1, Shisa5, Slc48a1, Sod1, Stx2, Syngr3,

Tonsl, Tram1, Tyro3, Vezf1, Ywhaq

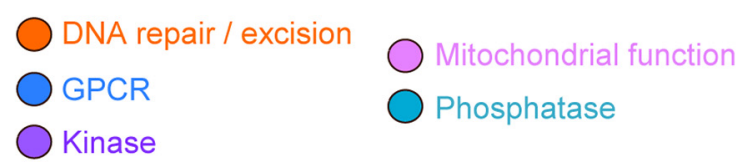

Transcription factor/cofactor

Ribosomal protein

Figure 6. TOP- and G-quartet-like elements are enriched in the upregulated genes identified with TRAP-seq. The motif analysis was performed on the list of upregulated genes identified with TRAP-seq after CIPN. We show that 3 motifs are significantly enriched in the 5' UTR, among them a TOP-like element, which consists of a " $C$ " or " $T$ " followed by a stretch of $5-15$ pyrimidines. Also, the analysis clearly reveals an enrichment in G-quartet-like motif as well as in an AG-rich motif.

sensitization, but effects in the spared nerve injury model of neuropathic pain were not as compelling (Moy et al., 2017, 2018). Given that our TRAP-seq data point to a clear role of altered translation regulation signaling in nociceptors in CIPN, we hypothesized that MNK-eIF4E signaling may play a crucial role in this model. In support of this hypothesis, mice harboring a mutation at the MNK phosphorylation site on eIF4E (eIF4E ${ }^{\text {S209A }}$ mice) treated with paclitaxel showed decreased mechanical (Fig. 7D) and thermal hypersensitivity (Fig. 7E) compared with their WT littermates. While this suggests decreased CIPN pain in the absence of eIF4E phosphorylation, we determined this empirically using the CPP paradigm (King et al., 2009) with retigabine as the conditioning agent, as has been described previously (Yang et al., 2014). Importantly, WT mice had a clear preference for the retigabine-paired chamber demonstrating relief of spontaneous pain. On the other hand, eIF4E ${ }^{S 209 A}$ mice showed no preference for the retigabine-paired chamber. This indicates an absence of spontaneous pain in these mice (Fig. $7 F$ ).

Given the strong behavioral phenotype of eIF4E $\mathrm{E}^{\mathrm{S} 209 \mathrm{~A}}$ mice in CIPN, we turned to a clinical candidate drug, eFT508 (Reich et al., 2018), which is a potent MNK1/2 inhibitor and blocks eIF4E phosphorylation in vitro and in vivo. We used this compound to examine whether targeted blockade of the MNK-eIF4E signaling axis inhibits and/or reverses paclitaxel-induced pain. We first tested the effect of eFT508 on cultured DRGs neurons. Treatment with eFT508 reduced eIF4E phosphorylation by $90 \%$ (Fig. $8 A$ ). Neither loss of eIF4E phosphorylation in eIF4E ${ }^{\text {S209A }}$ mice nor eFT508 treatment reduced bulk translation in the DRG in vivo
(Fig. 8-1, available at https://doi.org/10.1523/JNEUROSCI.266118.2018.f8-1). This parallels previous findings that Mnk1/2 signaling to eIF4E phosphorylation controls the translation of a specific subset of mRNAs (Gkogkas et al., 2014; Amorim et al., 2018). Paclitaxel-treated mice given eFT508 (10 mg/kg) after full development of CIPN showed a reversal of mechanical (Fig. 8B) and thermal hypersensitivity (Fig. $8 C$ ). We tested the specificity of the effect of eFT508 with dosing to WT and eIF4E ${ }^{\text {S209A }}$ mice. We also used this experiment to assess the potential development of tolerance to repeated dosing of eFT508. eFT508 (1 mg/kg) produced robust relief of mechanical hypersensitivity at this lower dose, and the effect was completely absent in eIF4E ${ }^{\text {S209A }}$ mice demonstrating the specificity (Fig. $8 D$ ). No signs of tolerance were observed in this experiment. Consistent with a key role for this signaling pathway in nociceptors, $80 \%$ of eGFP-L10a ${ }^{+}$ neurons exhibited strong p-eIF4E signal (Fig. $8 F, G$ ). No signal for the p-eIF4E antibody was observed in the eIF4E ${ }^{\mathrm{S} 209 \mathrm{~A}}$ mice, indicative of the specificity of the antibody (Fig. 8-2, available at https://doi.org/10.1523/JNEUROSCI.2661-18.2018.f8-2).

Our findings suggest a link between increased translation of mTOR complex proteins and MNK-mediated eIF4E phosphorylation as a causative factor in paclitaxel-induced neuropathy. However, mechanisms through which eIF4E phosphorylation might control mTOR signaling are not established. A possible connection between these parallel pathways (Richter and Sonenberg, 2005) is reciprocal translational regulation of mRNAs that encode signaling factors of the RagA-Ragulator complex mediated by MNK-dependent eIF4E phosphorylation. The RagA- 
A

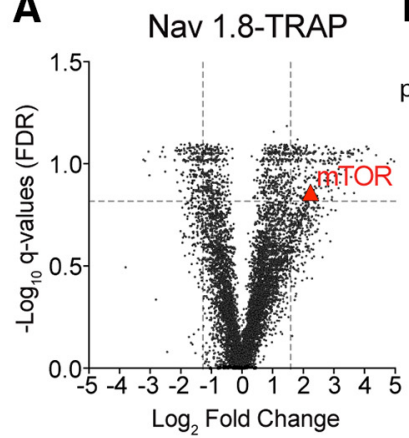

D

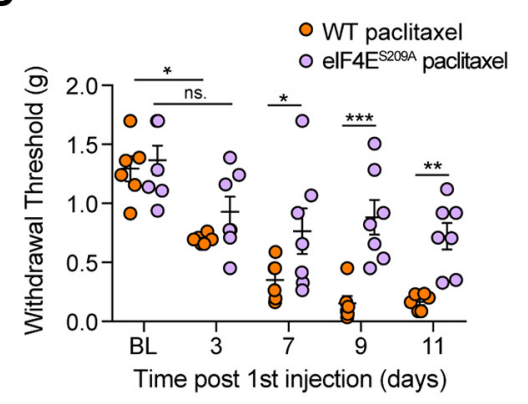

B

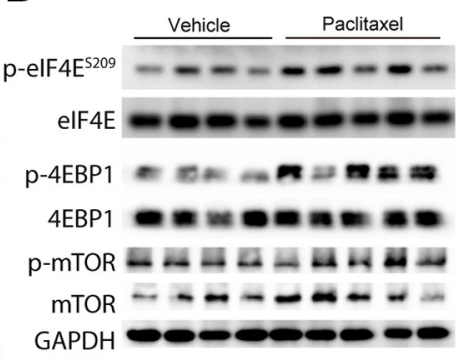

E

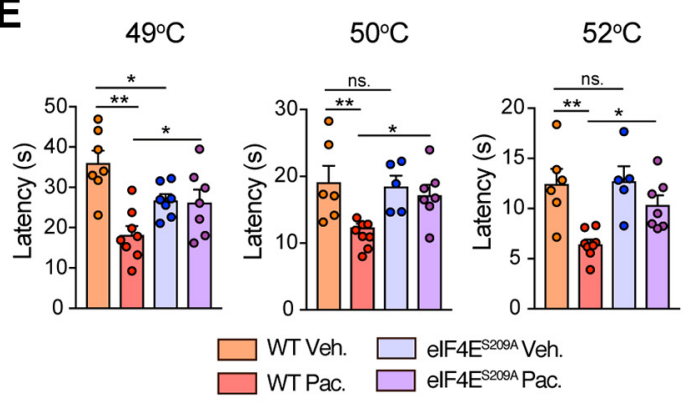

C

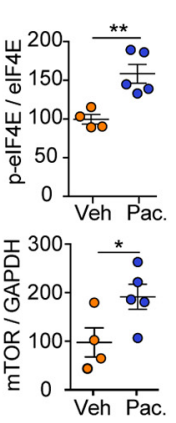$$
\text { 음 }
$$

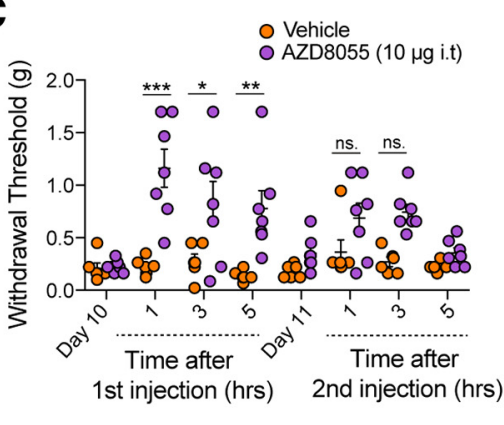

$F$

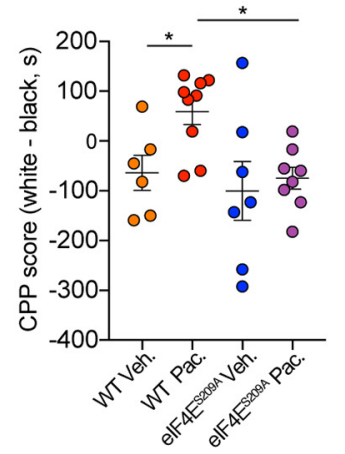

Figure 7. Enhanced elF4E signaling in nociceptors is responsible for evoked and spontaneous pain in paclitaxel-induced neuropathic pain. $A$, Volcano plot showing an increase in $m T O R$ mRNA translation in the DRGs after CIPN. $\boldsymbol{B}$, Immunoblotting shows an up-regulation of p-eIF4E, p-4EBP1,and $m$ TOR after paclitaxel treatment $\left(\mathrm{p}\right.$-eiF4E: Veh $=100 \pm 5.39$, Pac $=158 \pm 10.57,{ }^{* *} p=$ $0.0026, n=4-5 ; \mathrm{p}-4 \mathrm{EBP} 1: \mathrm{Veh}=100 \pm 9.8, \mathrm{Pac}=152 \pm 11.27,{ }^{*} p=0.012, n=4-5 ; \mathrm{p}-\mathrm{mTOR}:$ Veh $=100 \pm 10.8, \mathrm{Pac}=131 \pm 20.27, p=0.23, n=4-5 ; m T 0 R:$ Veh $=100 \pm 24.54$, $\left.\mathrm{Pac}=195 \pm 25.27,{ }^{*} p=0.025, n=4-5\right)$. C, Intrathecal injection of the $m T O R$ kinase inhibitor AZD8055 relieves mechanical allodynia compared to vehicle-treated animals after the first injection (Two way ANOVA: $F_{(7,88)}=3.93$; post-hoc Bonferroni: at $1 \mathrm{hr}:{ }^{* * *} p<0.001$, 3hrs: ${ }^{*} p=0.043,5 \mathrm{hrs:}{ }^{* *} p=0.0059$ ) but no significant effects were observed after the second injection. $\boldsymbol{D}$, elF4E ${ }^{\text {S209A }}$ mice show a deficit in development of paclitaxel-induced mechanical allodynia compared to WT animals. (Two way ANOVA: $F_{(4,44)}=3.14, p=0.023$ with a post-hoc test: at day $7:{ }^{*} p=0.045 ;$ at day 9: ${ }^{* * *} p=0.0003$; at day $11:{ }^{* *} p=0.0081$ elF4E ${ }^{S 209 A}$ vs WT, $\left.n=7\right)$. $E$, elF4E ${ }^{S 209 A}$ mice also exhibit a deficit in paclitaxel-induced thermal hyperalgesia compared to WT animals at $49^{\circ} \mathrm{C}$

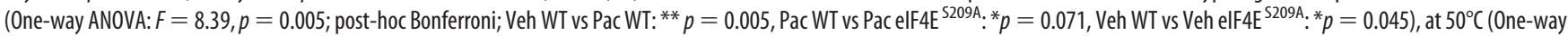
ANOVA: $F=6.23, p=0.0032$; post-hoc Bonferroni; Veh WT vs Pac WT: ${ }^{* *} p=0.0044$, Veh WT vs Veh elF4E ${ }^{\text {S209A. }}: p>0.99$, Pac WT vs PacelF4E $\left.{ }^{\text {S209A }}:{ }^{*} p=0.024\right)$ and 52 ${ }^{\circ} C(0$ ne-way ANOVA: $F=$ $7.78, p=0.0010$; post-hoc Bonferroni; Veh WT vs Pac WT: ${ }^{* *} p=0.0021$, Veh WT vs Veh elF4E ${ }^{\text {S209A. }} p>0.99$, Pac WT vs Pac elF4E $\left.{ }^{\text {S209A }: * ~} p=0.045\right)$. $F$, WT paclitaxel-treated mice show signs of ongoing pain in the (PP paradigm compared with WT vehicle (One way ANOVA: $F=4.36, p=0.012$, post-hoc Bonferroni Veh WT vs Pac WT: ${ }^{*} p=0.048$ ) and elF4E ${ }^{\text {S209A }}$ mice treated with paclitaxel, which did not show signs of spontaneous pain (One way ANOVA: $F=4.36,{ }^{*} p=0.012$, post-hoc Bonferroni Pac WT vs Pac elF4E ${ }^{\text {S209A. }}{ }^{*} p=0.019$ ). Figure 7-1 (available at https://doi.org/10.1523/JNEUROSCI.2661-18.2018.f7-1) shows validation of Esyt1 data and Figure 7-2 (available at https://doi.org/10.1523/JNEUROSCI.2661-18.2018.f7-2) shows additional Western blot controls.

Ragulator complex controls mTORC1 activity in response to amino acid flux across the lysosomal membrane (Sancak et al., 2010; Wolfson and Sabatini, 2017) and requires activity of the RagA, but not the RagB, GTPase (Efeyan et al., 2013, 2014). RagA exists in a complex with RagC, whereas RagB forms a complex with RagD (Efeyan et al., 2013, 2014). Our TRAP-seq comparison demonstrates that genes corresponding to the components of the RagA-Ragulator-mTORC1 complex are preferentially translated after paclitaxel treatment (Fig. 9A). In particular, there was a 3.5-fold increase in the number of normalized reads mapping to the Rraga mRNA, encoding the RagA GTPase amino acid sensor for mTORC1 (Fig. 9B, C).

Other components of the RagA-Ragulator-mTORC1 complex, including Lamtor5, Lamp2, Atp6v1a, Fkbp1a, Fkbp1b, Ywhaq, and Mtor, also showed a consistent increase in translation with paclitaxel treatment (Fig. 9A-D). Interestingly, known negative regulators of mTORC1, including Akt1s1, encoding PRAS40, and the $\gamma 2$ subunit of AMPK (Prkag2), showed decrease translation efficiency (Fig. 9A,D). These findings indicate a fundamental change in the mTORC1 signaling network in Nav1.8expressing neurons in CIPN that could be indicative of altered protein biosynthesis or related to other functions of mTORC1, such as lipid homeostasis (Saxton and Sabatini, 2017). Given the behavioral observations with eIF4E ${ }^{\mathrm{S} 209 \mathrm{~A}}$ mice, the effect of
eFT508 in CIPN, we further focused on translation regulation mechanisms as the key causative factor in paclitaxel-induced neuropathic pain.

We validated that RagA protein levels were increased in DRG by paclitaxel treatment (Fig. 9E). We also found that RagA protein expression was significantly lower in $e I F 4 E^{S 209 A}$ mice compared with WT mice, although mRNA levels were equal in the two strains of mice (Fig. 9F). These findings suggested that eIF4E phosphorylation controls RagA translation in CIPN. To test this, we treated eIF4E ${ }^{\text {S209A }}$ mice with paclitaxel and failed to observe an effect from paclitaxel on RagA protein in DRGs from these mice (Fig. 9G). Moreover, the MNK1/2 inhibitor eFT508 decreased RagA protein levels both in cultured DRG neurons (Fig. $10 A$ ) and in vivo (Fig. 10B). 4EBP1 phosphorylation was also decreased in the DRG of eFT508-treated mice linking altered RagA translation to downstream mTORC1 activity (Fig. 10B).

Two MNK isoforms are known to phosphorylate eIF4E, however; MNK2 shows constitutive kinase activity, whereas MNK1 is induced by cellular stimuli (Ueda et al., 2004). We reasoned that MNK1-mediated phosphorylation of eIF4E might control RagA protein expression and regulate paclitaxel-induced CIPN. $M N K 1^{-1-}$ mice showed a $40 \%$ reduction in RagA protein levels in DRG compared with WT and a significant reduction in eIF4E phosphorylation while upstream signaling pathways were unchanged 
A

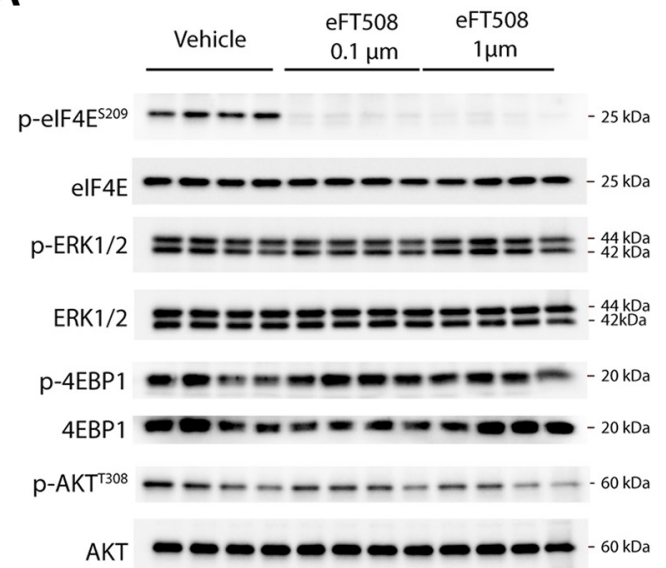

B

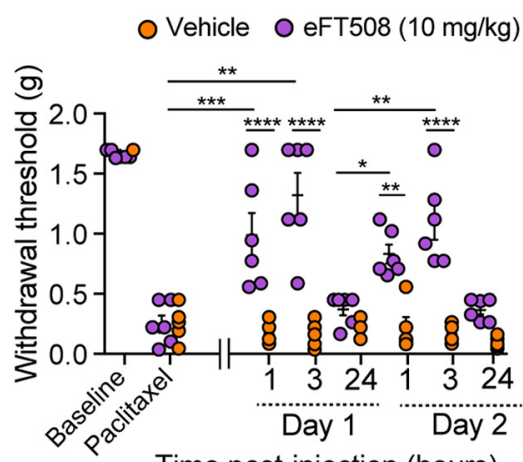

Time post-injection (hours)
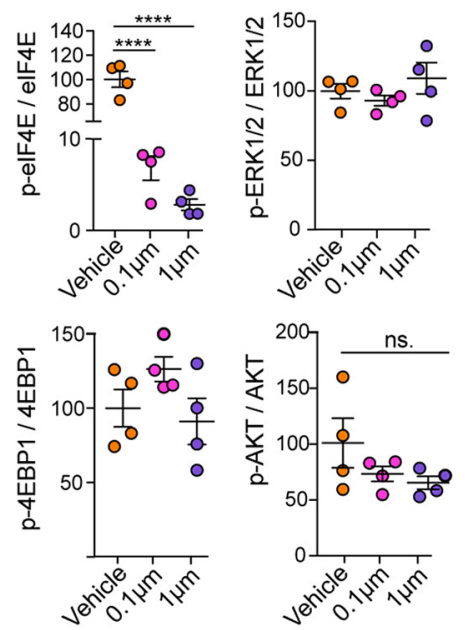

C

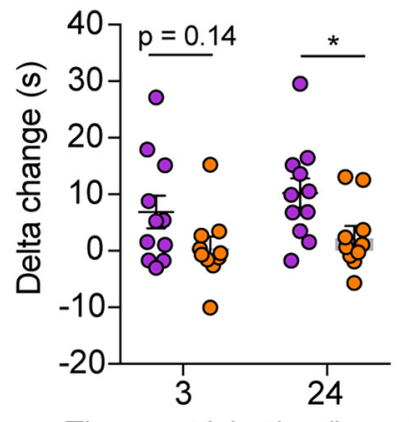

Time post-injection (hours)
E

Dorsal root ganglia
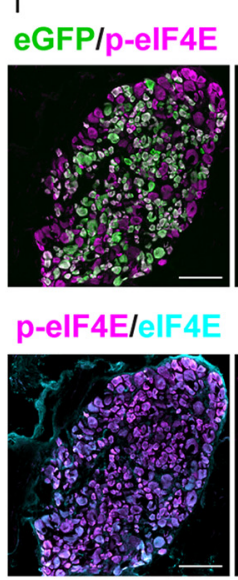

Merged
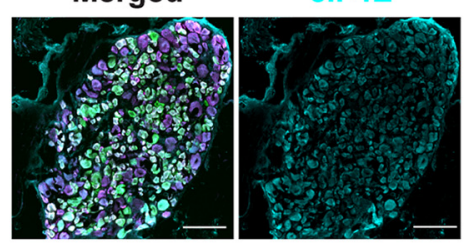

$\mathbf{F}$

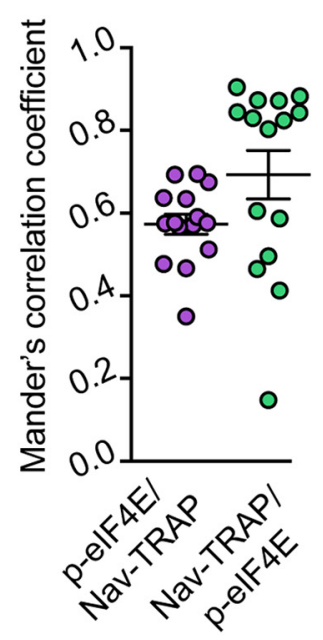

Time after 1st injection of paclitaxel (days)

Figure 8. The specific MNK inhibitor, eFT508, reverses CIPN. A, eFT508 significantly reduced the level of elF4E phosphorylation at 0.1 and $1 \mu$ M after 1 hr (One way ANOVA: $F=205.2, p<$ 0.0001; post-hoc Tukey: ${ }^{* * *} p<0.0001$ ), without affecting other signaling pathways in cultured mouse DRG neurons. $B$, Acute treatment with eFT08 relieves mechanical allodynia compared to vehicle after the 1st (Two way ANOVA: $F_{(7,63)}=14.53$, post-hoc Bonferroni at 1 and 3 hrs (eFT508 vs vehicle: ${ }^{* * *} p<0.0001$ ) and the 2 nd injection (Two way ANOVA: $F_{(7,63)}=14.53$, post-hoc Bonferroni at $1 \mathrm{hr}$ (eFT508 vs vehicle: ${ }^{* *} p<0.01$ ) and $3 \mathrm{hrs}$ (eFT508 vs vehicle: ${ }^{* * *} p<0.0001$ ). Also, eFT508 transiently relieves mechanical allodynia on day 1 (Two way ANOVA: $F_{(7,63)}=14.53$, post-hoc Bonferroni eFT508-BL vs efT508-1hr: ***p $<0.001$ and eFT508-BL vs eFT508-3hrs: ${ }^{* *} p=0.0012$ ) and day 2 (Two way ANOVA: $F_{(7.63)}=14.53$, post-hoc Bonferroni eFT508-BL vs eFT508-1hr: ${ }^{*} p=0.036$ and eFT508-BL vs eFT508-3hrs: $\left.{ }^{* *} p=0.0021\right)$. C, Acute treatment with eFT508 did not significantly attenuate thermal hyperalgesia at 3 hrs (Two way ANOVA: $F_{(1,38)}=$ 8.46 , post-hoc Sidak: $p=0.14$ ) but a significant effect was observed at 24 hrs (Two way ANOVA: $F(1,38)=8.46$, post-hoc Sidak: $\left.{ }^{*} p<0.05\right)$. D , elF4E $\mathrm{E}^{5209 A}$ mice showed a deficit in the development of CIPN compared to WT mice (Two way ANOVA: $F_{(2,117)}=15,82, p<0.0001$ with post-hoc test at day 3 : WT vs elF4E ${ }^{\text {S209A }: ~}{ }^{*} p=0.019$, WT vs elF4E ${ }^{\text {S209A }}$ (eFT508): ** $p=0.0065$; at day 5 WT vs

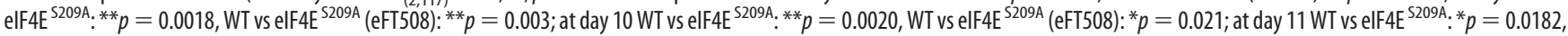
WT v elF4E ${ }^{\text {S209A }}$ (eFT508): ${ }^{*} p=0.028$; at day 12 WT vs elF4E ${ }^{\text {S209A }: * ~} p=0.022$, WT vs elF4E ${ }^{\text {S209A }}$ (eFT508): ${ }^{*} p=0.044$. Chronic treatment with 1 mg/kg eFT508 reverses established CIPN without inducing tolerance in WT mice (Two way ANOVA: $F(2,117)=15,82: p<0.0001$ with post-hoc test day 10: (BL vs $\left.2 \mathrm{~h},{ }^{* *} p=0.0023\right)$, day 11: (BL vs $\left.2 \mathrm{~h},{ }^{*} p=0.045\right)$ and day 12: (BL vs $2 \mathrm{~h}$, ${ }^{*} p=$ 0.0497 ) but was completely without effect in elF4ES209A mice. $\boldsymbol{E}$, and $\boldsymbol{F}$, p-elF4E is highly expressed in Nav1.8-positive DRG neurons and approximatively 80\% of the eGFPe signal co-localizes with p-elF4E. Scale bars, $100 \mu \mathrm{m}$. Figure 8-1 (available at https://doi.org/10.1523/JNEUROSCI.2661-18.2018.f8-1) shows SuNSET assay on DRG neurons and Figure 8-2 (available at https://doi.org/ 10.1523/JNEUROSCI.2661-18.2018.f8-2) shows validation of anti-p-elF4E antibody.

(Fig. 10C; Fig. 10-1, available at https://doi.org/10.1523/ JNEUROSCI.2661-18.2018.f10-1). When we coexamined eIF4E phosphorylation with RagA expression in mouse DRG we observed correlated expression for RagA and p-eIF4E. This was in- creased by paclitaxel treatment and strongly suppressed by eFT508 with an $80 \%$ correlation coefficient indicating that increases or decreases in eIF4E phosphorylation can reliably influence the level of RagA translation (Fig. 10D). We then assessed 
A

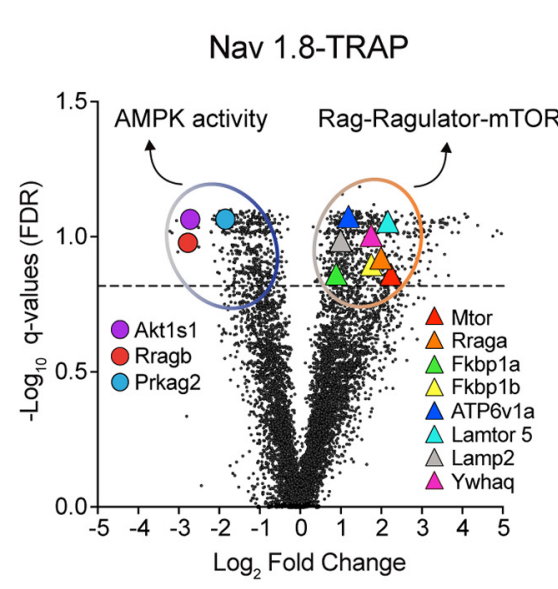

RagA (Rraga)

Chr4 (+) 86.575.668-86.577.285
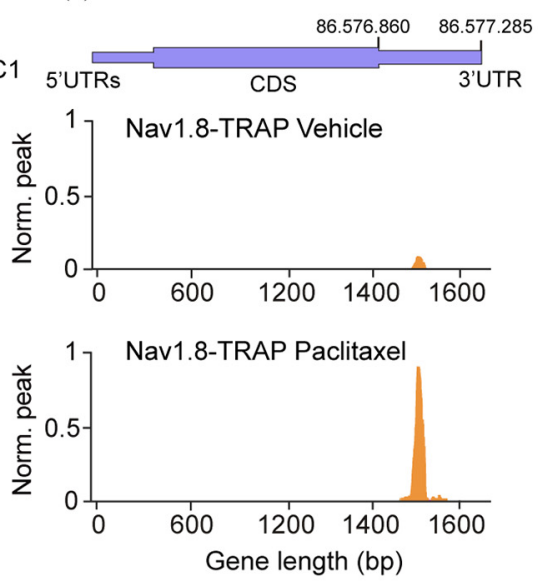

C

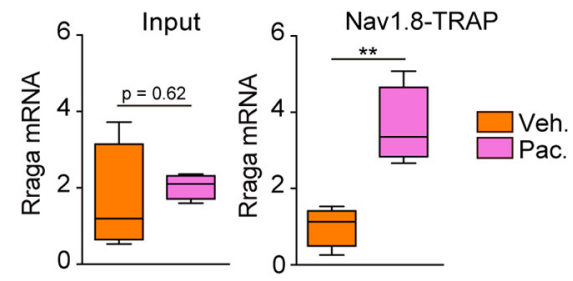

D

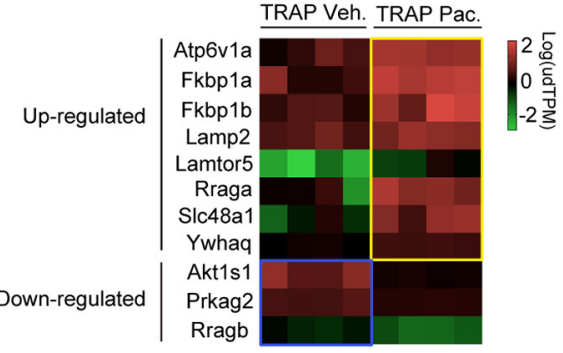

E

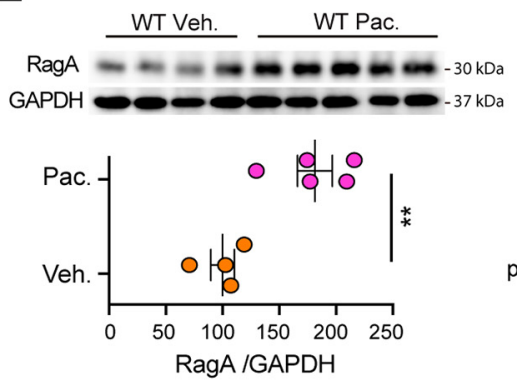

F

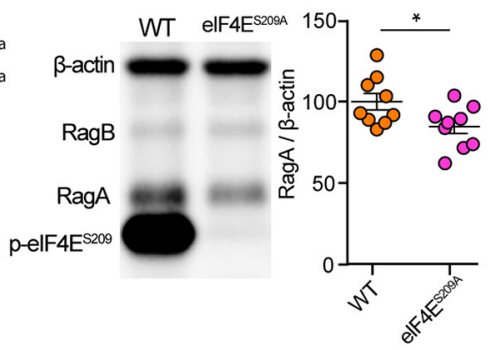

G

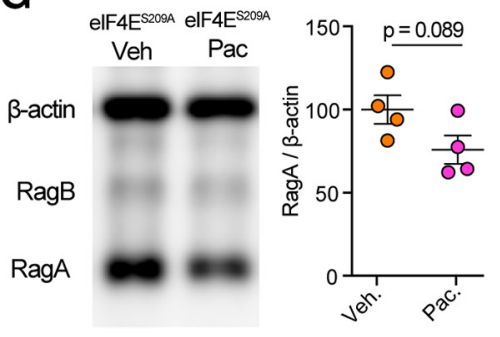

Figure 9. Increased translation of RagA-Ragulator-mTORC1 complex mRNAs in CIPN. $A$, Volcano plot shows an increase in translation efficiency for mRNAs encoding proteins associated with the Rag-Ragulator-mTORC1 complex. B, Distribution of the normalized reads on the RagA gene (Rraga) showing a prominent peak in the TRAP fraction after CIPN compared to Veh while no changes are observed in the Input fraction. $C$, Normalized TPM for the Rraga mRNA shows no differences in the input (RagA: Veh $=1.65 \pm 0.71$, Pac: $2.04 \pm 0.17 p=0.62$ ) while a significant increase is observes in the TRAP fraction (RagA: Veh $=1.004 \pm 0.26$, Pac: $3.6 \pm 0.51{ }^{* *} p=0.0043$ ). $\boldsymbol{D}$, Heatmap showing increased or decreased translation of the mRNAs encoding proteins of the Ragulator-RagA-mTORC1 complex after CIPN. E, Immunoblot showing an increase in RagA protein levels in DRGs after CIPN compared to Veh (RagA:Veh $=100 \pm 10.33$, Pac $=181 \pm 15.35, * * p=$ $0.0043, n=4-5) . F$, Immunoblot showing a decrease in RagA protein levels in the elF4E ${ }^{5209 A}$ mice compared to WT (RagA: Veh $=100 \pm 5.05$, Pac $=84.6 \pm 4.32,{ }^{*} p=0.035, n=9$ ) while no differences were observed in mRNA levels (RagA: Veh $=1.007 \pm 0.067, \mathrm{Pac}=1.176 \pm 0.01, p=0.084, n=4)$ ). G, Immunoblot showing no differences in the DRG level of RagA protein between elF4E ${ }^{\text {S209A }}$ vehicle- and paclitaxel-treated mice (RagA : Veh $\left.=100 \pm 8.567, \mathrm{Pac}=75 \pm 8.46, p=0.089, n=4\right)$.

paclitaxel-induced CIPN in $M N K 1^{-1-}$ mice and observed a profound deficit in the development of mechanical hypersensitivity (Fig. 10E) consistent with observations in $e I F 4 E^{S 209 A}$ mice. Finally, we examined whether transient MNK1/2 inhibition could decrease spontaneous activity in DRG neurons taken from paclitaxel-treated mice. These neurons showed robust spontaneous activity that was strongly suppressed by eFT508 treatment (Fig. 10F). Approximately 20 min of treatment with eFT508 was needed to reduce spontaneous activity in most neurons, and this effect was reversible, indicating that eFT508 is not toxic to DRG neurons in vitro.

\section{Discussion}

We used Nav1.8-positive neuronal translational profiling in the paclitaxel model of CIPN pain to comprehensively characterize the nociceptor translatome in mice with and without neuropathic pain. The data provide a unique resource for probing translational control in pain plasticity and reveal high-quality targets for the potential generation of disease modifying therapies for a currently intractable disease (Seretny et al., 2014; Ma et al., 2018). Our work demonstrates broad changes in regulation of the mTORC1 and MNK-eIF4E signaling network in CIPN that reveals a complex interplay between eIF4E-mediated translation control of RragA mRNA and mTORC1 function (Fig. 10G). Our experiments support a model wherein MNK1-mediated phosphorylation of eIF4E controls the translation of RragA mRNA creating a previously unknown link between these distinct signaling pathways. In the context of CIPN, increased eIF4E phosphorylation leads to enhanced Rraga mRNA translation and RagA protein levels driving $\mathrm{mTORC} 1$ activation and neuropathic pain. Our findings demonstrate that MNK and eIF4E phosphorylation can be targeted genetically or with eFT508 (also known as Tomivosertib), a drug in late-phase clinical trials as a means to prevent or reverse CIPN pain. These discoveries can potentially be used to enhance the efficacy of cancer chemotherapy treatment by reducing the primary dose-limiting side effect of chemotherapy (Seretny et al., 2014; Ma et al., 2018). Our findings could also improve the quality of life of people who suffer from CIPN that continues after treatment because we have shown that blocking MNK-eIF4E signaling plays a role in initiating and maintaining CIPN.

The global profile we report of translation provides an independent confirmation for a variety of findings in the CIPN and chronic pain literature. This speaks to the powerful nature of the use of the TRAP-seq technique to gain insight into disease mechanisms in a cell type-specific fashion. In our gene ontology analysis, we identified both reactive oxygen signaling (Doyle et al., 
A

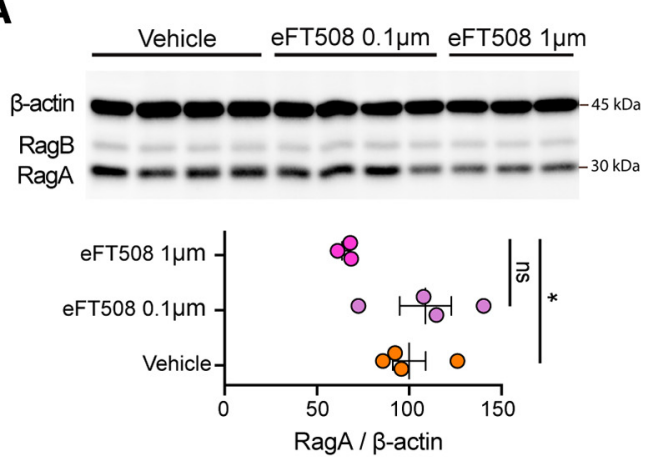

B

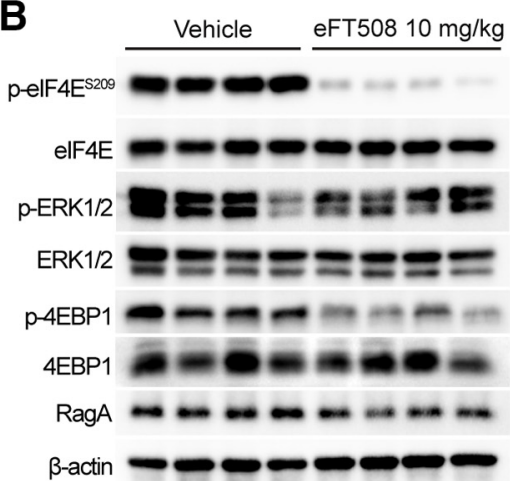

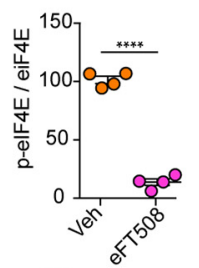
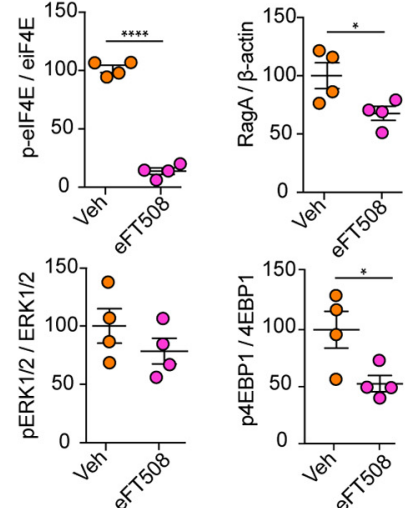

C

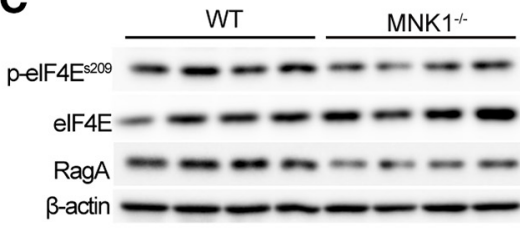

D
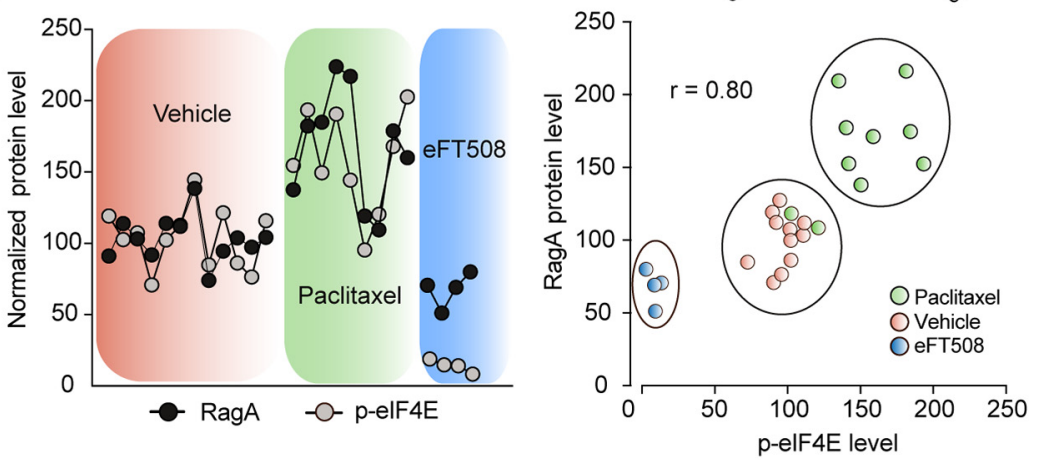

E

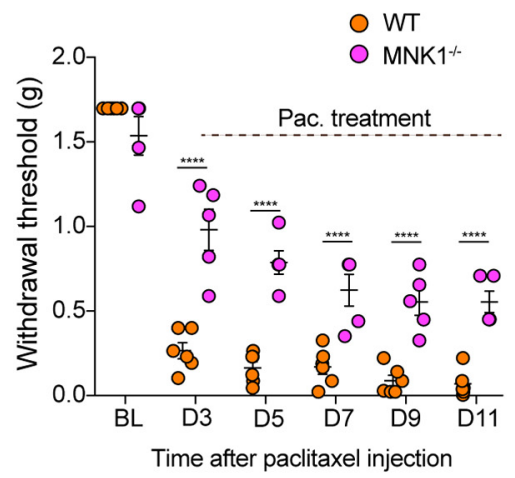

$\mathbf{F}$
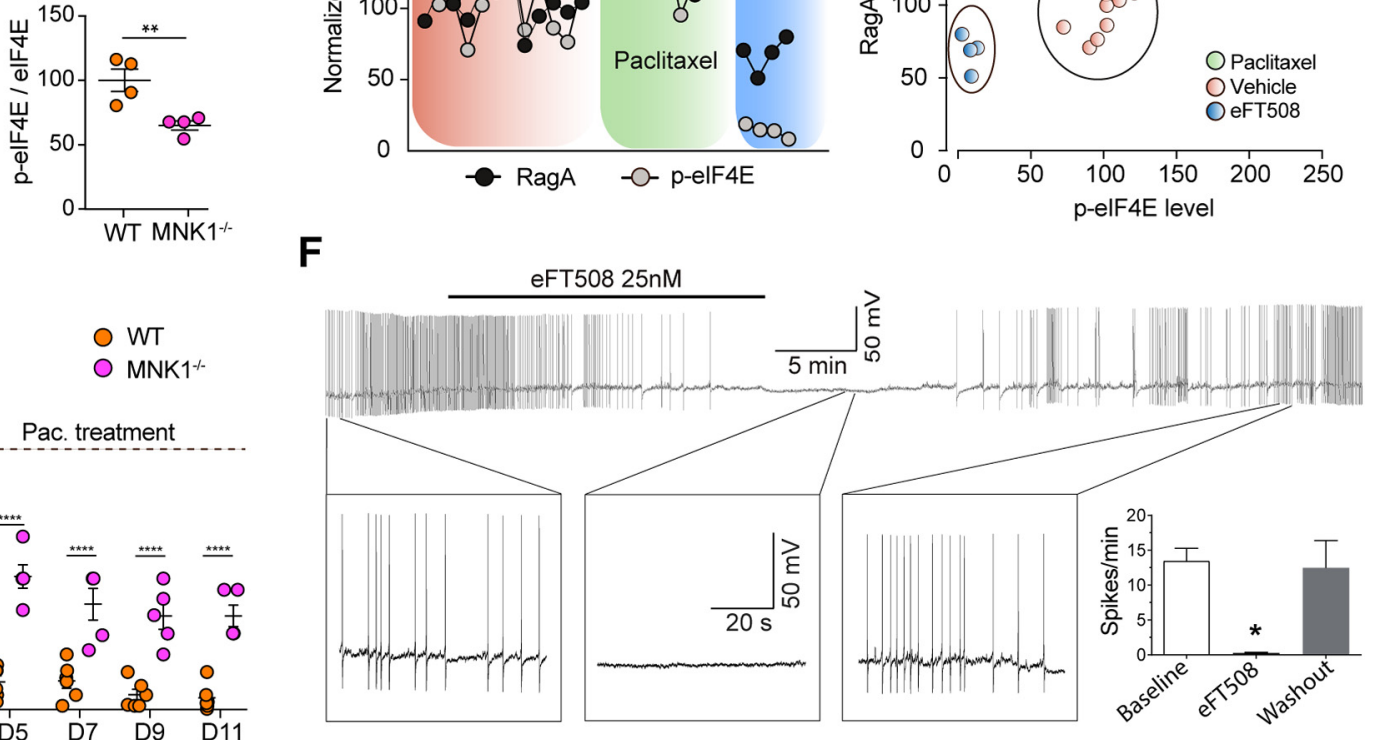

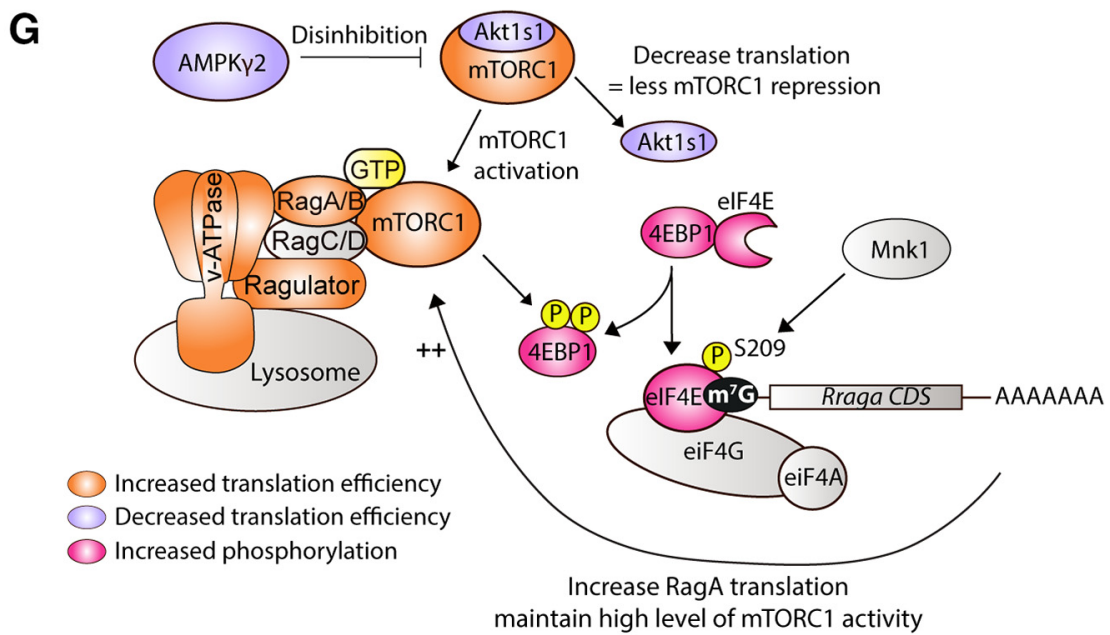

Figure 10. The MNK1-elF4E axis controls the translation of the RagA GTPase in CIPN. $\boldsymbol{A}$, Immunoblot showing a decrease in RagA protein level after treatment with eFT508 at $1 \mu \mathrm{M}$ for $1 \mathrm{hr}$ (0ne way ANOVA: $F=4.55, p=0.040$, post-hoc Sidak Veh WT vs: $\left.1 \mu \mathrm{M}^{*} p=0.042\right)$. $\boldsymbol{B}$, Immunoblot showing a significant decrease in the level of $p$-elF4E and RagA after eFT508 treatment in DRGs in vivo (p-elF4E: Veh $=100 \pm 2.33$, eFT508: $10 \pm 2.43,{ }^{* * *} p<0.0001, n=4$; p4EBP1: Veh $=100 \pm 16.03$, eFT508 $=53.12 \pm 7.03$, (Figure legend continues.) 
2012; Duggett et al., 2016) and mitochondrial function as key changes occurring in CIPN. Both of these are well-known mechanisms of CIPN with a great deal of recent focus in the field placed on mitochondrial dysfunction (Flatters and Bennett, 2006; Flatters, 2015; Griffiths and Flatters, 2015). Our work provides a comprehensive snapshot of changes in translation of mRNAs that regulate mitochondrial function in CIPN. We also confirm the upregulation of translation of several mRNAs that have also been linked to functional pathology in CIPN. Chief among these are Trpv1 (Li et al., 2015), an ion channel well known to contribute to many different types of pain, and caspase 6 , an enzyme that has been linked to many different types of chronic pain where it seems to regulate tumor necrosis factor $\alpha$ signaling via an extracellular mechanism (Berta et al., 2014). Our TRAP-seq findings independently support the conclusion that enhanced nociceptor translation of caspase 6 contributes to CIPN (Berta et al., 2017).

CIPN has traditionally been viewed as a length-dependent neuropathy that primarily affects the hands and feet, mainly in the glabrous skin areas (Seretny et al., 2014). There is support for distinct mechanisms of altered excitability in nociceptors that innervate glabrous skin caused by chemotherapy treatment that potentially explain this relatively selective pain phenotype (Yilmaz and Gold, 2016). However, several recent clinical studies have demonstrated that pain is more widespread in CIPN, although usually more intense in the hands and feet (Eckhoff et al., 2015; Ventzel et al., 2016). These studies also indicate that this widespread pain is persistent in many people who continue to suffer from CIPN more than a year after cessation of treatment (Eckhoff et al., 2015). We examined DRG neuron excitability in mice treated with paclitaxel at all DRG levels, including thoracic DRGs that innervate the trunk. Consistent with the clinical studies cited above, we found that DRG neuron excitability is increased at all vertebral levels with paclitaxel treatment. Moreover, our TRAP-seq data with DRGs taken from all levels showed strong changes in translation regulation in DRG nociceptors. If only a subset of DRG neurons were influenced by paclitaxel treatment alteration in ribosome bound mRNAs in CIPN would likely not have been detectable with our experimental approach. Our studies were undertaken soon after the cessation of paclitaxel treatment. In future work, it will be interesting to assess whether these electrophysiological and translatome changes persist at later stages of CIPN. Nevertheless, our work supports the conclusion that the effects of chemotherapy on DRG neurons are widespread and not limited to the longest axons.

Translation regulation is a key contributor to chronic pain (Jiménez-Díaz et al., 2008; Géranton et al., 2009; Obara et al., 2012; Moy et al., 2017; Barragán-Iglesias et al., 2018; Khoutorsky and Price, 2018). Our findings offer unprecedented insight into

$\leftarrow$

(Figurelegend continued.) $\quad{ }^{*} p=0.037$; RagA:Veh $=100 \pm 11.03$, eFT508: $67 \pm 6.02,{ }^{*} p=$ $0.042, n=4$. C, Immunoblot showing a significant decrease in the level of p-elF4E (Veh $=$ $100 \pm 8.63$, MNK1 $\left.^{-1-}: 64.98 \pm 3.63,{ }^{* *} p=0.0094, n=4\right)$ and RagA $($ Veh $=100 \pm 2.54$, MNK1 $\left.{ }^{-1-}: 67 \pm 5.70,{ }^{* *} p<0.0010, n=4\right)$ in MNK1 ${ }^{-1-}$ mice compared to WT. D, Coexpression level of RagA and p-elF4E in vehicle-, paclitaxel- and eFT508-treated mice shows high correlation between DRG samples. $E$, MNK1 ${ }^{-1-}$ show a deficit in development of paclitaxel-induced mechanical allodynia compared to WT animals (Two way ANOVA: $F_{(5,45)}=$ $13.45, p<0.0001$ with a post-hoc test: at day $3,5,7,9^{* * *} p<0.0001$ MNK1 $^{-1-}$ vs WT, $n=$ 7). $\boldsymbol{F}$, eFT508 treatment decreases spontaneous activity found in DRG neurons after paclitaxel treatment in a reversible fashion. Paired t-test, ${ }^{*} p<0.05$. G, Summary diagram showing proposed MNK1-elF4E regulation of RagA translation and its influence on mTORC1 activity. Figure 10-1 (available at https://doi.org/10.1523/JNEUROSCI.2661-18.2018.f10-1) shows additional Western blot data. how translation regulation signaling is enhanced in Nav1.8positive neurons in neuropathic pain. Previous studies have shown that peripheral nerve injury enhances mTORC1 signaling in sensory neurons (Géranton et al., 2009; Melemedjian et al., 2011), and a very recent study demonstrates that local translation of the Mtor mRNA is a key regulatory of the intrinsic neuronal response to DRG neuron axonal injury (Terenzio et al., 2018). Our previous work demonstrated that MNK-eIF4E signaling is important for many types of pain sensitization (Moy et al., 2017, 2018). However, in the spared nerve injury model of neuropathic pain, MNK-eIF4E signaling primarily contributes to cold hypersensitivity with a substantially smaller effect on mechanical hypersensitivity (Moy et al., 2017). Here we show a strong impact of MNK-eIF4E signaling on mechanical and heat hypersensitivity. Additionally, we show a contribution to spontaneous pain, a clinically relevant consideration that can be readily reversed in the paclitaxel model of CIPN. A key aspect of our current work is the demonstration of an integrated signaling network of mTORC1 and MNK-eIF4E that is persistently activated in CIPN. An important remaining question is how this signaling network is driven. We discovered a large number of translationally upregulated mRNAs that compose the interface of mTORC1 signaling with the lysosome (Efeyan et al., 2012; Bar-Peled and Sabatini, 2014) (Fig. 10G). This identifies lysosomal amino acid efflux as a likely contributor to CIPN and demonstrates how this fundamental cellular process is linked to changes in gene expression that drive increased DRG neuron excitability in this form of neuropathic pain. Importantly, we identify many ion channels (TRPV1, $\alpha 6$ nicotinic receptors, downregulated, P2X2), GPCRs (Mrgprd), and enzymes (caspase 6) that are translationally regulated in Nav1.8positive neurons by paclitaxel treatment providing a link between enhanced mRNA translation and neuronal excitability.

Our electrophysiological findings demonstrate that eFT508 suppresses nociceptor spontaneous activity in DRG neurons isolated from mice treated with paclitaxel within $\sim 20 \mathrm{~min}$. Nociceptor spontaneous activity has been linked to spontaneous pain, which is a key behavioral manifestation of neuropathic pain in humans and preclinical models (Price and Gold, 2018). Consistent with our electrophysiological findings, we did not observe signs of CIPN-induced spontaneous pain using the CPP model in mice lacking eIF4E phosphorylation. The rapid onset of effect of eFT508 in electrophysiological and behavioral experiments could point to an effect of MNK signaling on factors other than eIF4E phosphorylation. However, we do not think this is the case because there were no additional effects of eFT508 when it was given to eIF4E phosphorylation mutant mice. Our findings suggest that nociceptor excitability is controlled by the translation of a subset of mRNAs that encode proteins with short half-lives. We hypothesize that these plasticity-mediating proteins may be scaffolding proteins that regulate rapid trafficking of ion channels to and from the cell membrane (Jeske, 2012, 2015). Identifying these proteins will be a goal moving ahead. Importantly, our TRAP-seq datasets identify a number of candidates, including Arl6, Dlg2, and Ywhaq genes.

The key finding emerging from our work is that inhibiting MNK-eIF4E signaling disrupts a novel translational circuit driving enhanced mTORC1 activity and nociceptor excitability in neuropathic pain. We propose a model wherein this circuit is driven by MNK1-eIF4E-mediated translation of Rraga mRNA. Because MNK inhibitors are in Phase II clinical trials (Reich et al., 2018), this could provide a path for rapid development of a neuropathic pain therapeutic. 


\section{References}

Amorim IS, Kedia S, Kouloulia S, Simbriger K, Gantois I, Jafarnejad SM, Li Y, Kampaite A, Pooters T, Romanò N, Gkogkas CG (2018) Loss of eIF4E phosphorylation engenders depression-like behaviors via selective mRNA translation. J Neurosci 38:2118-2133. CrossRef Medline

Bar-Peled L, Sabatini DM (2014) Regulation of mTORC1 by amino acids. Trends Cell Biol 24:400-406. CrossRef Medline

Barragán-Iglesias P, Lou TF, Bhat VD, Megat S, Burton MD, Price TJ, Campbell ZT (2018) Inhibition of Poly(A)-binding protein with a synthetic RNA mimic reduces pain sensitization in mice. Nat Commun 9:10. CrossRef Medline

Bennett GJ, Doyle T, Salvemini D (2014) Mitotoxicity in distal symmetrical sensory peripheral neuropathies. Nat Rev Neurol 10:326-336. CrossRef Medline

Berta T, Park CK, Xu ZZ, Xie RG, Liu T, Lü N, Liu YC, Ji RR (2014) Extracellular caspase- 6 drives murine inflammatory pain via microglial TNFalpha secretion. J Clin Invest 124:1173-1186. CrossRef Medline

Berta T, Perrin FE, Pertin M, Tonello R, Liu YC, Chamessian A, Kato AC, Ji RR, Decosterd I (2017) Gene expression profiling of cutaneous injured and non-injured nociceptors in SNI animal model of neuropathic pain. Sci Rep 7:9367. CrossRef Medline

Campbell JN, Meyer RA (2006) Mechanisms of neuropathic pain. Neuron 52:77-92. CrossRef Medline

Chaplan SR, Bach FW, Pogrel JW, Chung JM, Yaksh TL (1994) Quantitative assessment of tactile allodynia in the rat paw. J Neurosci Methods 53:5563. CrossRef Medline

Corder G, Tawfik VL, Wang D, Sypek EI, Low SA, Dickinson JR, Sotoudeh C, Clark JD, Barres BA, Bohlen CJ, Scherrer G (2017) Loss of mu opioid receptor signaling in nociceptors, but not microglia, abrogates morphine tolerance without disrupting analgesia. Nat Med 23:164-173. CrossRef Medline

Cowie AM, Moehring F, O’Hara C, Stucky CL (2018) Optogenetic inhibition of CGRPalpha sensory neurons reveals their distinct roles in neuropathic and incisional pain. J Neurosci 38:5807-5825. CrossRef Medline

Daou I, Beaudry H, Ase AR, Wieskopf JS, Ribeiro-da-Silva A, Mogil JS, Séguéla P (2016) Optogenetic silencing of Nav1.8-positive afferents alleviates inflammatory and neuropathic pain. eNeuro 3:ENEURO.014015.2016. CrossRef Medline

Denk F, McMahon SB, Tracey I (2014) Pain vulnerability: a neurobiological perspective. Nat Neurosci 17:192-200. CrossRef Medline

Doyle T, Chen Z, Muscoli C, Bryant L, Esposito E, Cuzzocrea S, Dagostino C, Ryerse J, Rausaria S, Kamadulski A, Neumann WL, Salvemini D (2012) Targeting the overproduction of peroxynitrite for the prevention and reversal of paclitaxel-induced neuropathic pain. J Neurosci 32:61496160. CrossRef Medline

Duggett NA, Griffiths LA, McKenna OE, de Santis V, Yongsanguanchai N, Mokori EB, Flatters SJ (2016) Oxidative stress in the development, maintenance and resolution of paclitaxel-induced painful neuropathy. Neuroscience 333:13-26. CrossRef Medline

Eckhoff L, Knoop A, Jensen MB, Ewertz M (2015) Persistence of docetaxelinduced neuropathy and impact on quality of life among breast cancer survivors. Eur J Cancer 51:292-300. CrossRef Medline

Efeyan A, Zoncu R, Sabatini DM (2012) Amino acids and mTORC1: from lysosomes to disease. Trends Mol Med 18:524-533. CrossRef Medline

Efeyan A, Zoncu R, Chang S, Gumper I, Snitkin H, Wolfson RL, Kirak O, Sabatini DD, Sabatini DM (2013) Regulation of mTORC1 by the rag GTPases is necessary for neonatal autophagy and survival. Nature 493: 679-683. CrossRef Medline

Efeyan A, Schweitzer LD, Bilate AM, Chang S, Kirak O, Lamming DW, Sabatini DM (2014) RagA, but not RagB, is essential for embryonic development and adult mice. Dev Cell 29:321-329. CrossRef Medline

Finnerup NB, Attal N, Haroutounian S, McNicol E, Baron R, Dworkin RH, Gilron I, Haanpää M, Hansson P, Jensen TS, Kamerman PR, Lund K, Moore A, Raja SN, Rice AS, Rowbotham M, Sena E, Siddall P, Smith BH, Wallace M (2015) Pharmacotherapy for neuropathic pain in adults: a systematic review and meta-analysis. Lancet Neurol 14:162-173. CrossRef Medline

Flatters SJ (2015) The contribution of mitochondria to sensory processing and pain. Prog Mol Biol Transl Sci 131:119-146. CrossRef Medline

Flatters SJ, Bennett GJ (2006) Studies of peripheral sensory nerves in paclitaxel-induced painful peripheral neuropathy: evidence for mitochondrial dysfunction. Pain 122:245-257. CrossRef Medline
Furic L, Rong L, Larsson O, Koumakpayi IH, Yoshida K, Brueschke A, Petroulakis E, Robichaud N, Pollak M, Gaboury LA, Pandolfi PP, Saad F, Sonenberg N (2010) eIF4E phosphorylation promotes tumorigenesis and is associated with prostate cancer progression. Proc Natl Acad Sci U S A 107:14134-14139. CrossRef Medline

Géranton SM, Jiménez-DíazL, Torsney C, Tochiki KK, Stuart SA, Leith JL, Lumb BM, Hunt SP (2009) A rapamycin-sensitive signaling pathway is essential for the full expression of persistent pain states. J Neurosci 29: 15017-15027. CrossRef Medline

Gereau RW 4th, Sluka KA, Maixner W, Savage SR, Price TJ, Murinson BB, Sullivan MD, Fillingim RB (2014) A pain research agenda for the 21st century. J Pain 15:1203-1214. CrossRef Medline

Gkogkas CG, Khoutorsky A, Cao R, Jafarnejad SM, Prager-Khoutorsky M, Giannakas N, Kaminari A, Fragkouli A, Nader K, Price TJ, Konicek BW, Graff JR, Tzinia AK, Lacaille JC, Sonenberg N (2014) Pharmacogenetic inhibition of eIF4E-dependent Mmp9 mRNA translation reverses fragile X syndrome-like phenotypes. Cell Rep 9:1742-1755. CrossRef Medline

Glusman G, Caballero J, Robinson M, Kutlu B, Hood L (2013) Optimal scaling of digital transcriptomes. PLoS One 8:e77885. CrossRef Medline

Gold MS, Gebhart GF (2010) Nociceptor sensitization in pain pathogenesis. Nat Med 16:1248-1257. CrossRef Medline

Griffiths LA, Flatters SJ (2015) Pharmacological modulation of the mitochondrial electron transport chain in paclitaxel-induced painful peripheral neuropathy. J Pain 16:981-994. CrossRef Medline

Haroutounian S, Nikolajsen L, Bendtsen TF, Finnerup NB, Kristensen AD, Hasselstrøm JB, Jensen TS (2014) Primary afferent input critical for maintaining spontaneous pain in peripheral neuropathy. Pain 155:12721279. CrossRef Medline

Haroutounian S, Ford AL, Frey K, Nikolajsen L, Finnerup NB, Neiner A, Kharasch ED, Karlsson P, Bottros MM (2018) How central is central poststroke pain? The role of afferent input in poststroke neuropathic pain: a prospective, open-label pilot study. Pain 159:1317-1324. CrossRef Medline

Heiman M, Schaefer A, Gong S, Peterson JD, Day M, Ramsey KE, SuárezFariñas M, Schwarz C, Stephan DA, Surmeier DJ, Greengard P, Heintz N (2008) A translational profiling approach for the molecular characterization of CNS cell types. Cell 135:738-748. CrossRef Medline

Heiman M, Kulicke R, Fenster RJ, Greengard P, Heintz N (2014) Cell typespecific mRNA purification by translating ribosome affinity purification (TRAP). Nat Protoc 9:1282-1291. CrossRef Medline

Hu G, Huang K, Hu Y, Du G, Xue Z, Zhu X, Fan G (2016) Single-cell RNA-seq reveals distinct injury responses in different types of DRG sensory neurons. Sci Rep 6:31851. CrossRef Medline

Ingolia NT, Brar GA, Rouskin S, McGeachy AM, Weissman JS (2012) The ribosome profiling strategy for monitoring translation in vivo by deep sequencing of ribosome-protected mRNA fragments. Nat Protoc 7:15341550. CrossRef Medline

Jeske NA (2012) Somatosensory scaffolding structures. Front Mol Neurosci 5:2. CrossRef Medline

Jeske NA (2015) Peripheral scaffolding and signaling pathways in inflammatory pain. Prog Mol Biol Transl Sci 131:31-52. CrossRef Medline

Ji RR, Samad TA, Jin SX, Schmoll R, Woolf CJ (2002) p38 MAPK activation by NGF in primary sensory neurons after inflammation increases TRPV 1 levels and maintains heat hyperalgesia. Neuron 36:57-68. CrossRef Medline

Ji RR, Chamessian A, Zhang YQ (2016) Pain regulation by non-neuronal cells and inflammation. Science 354:572-577. CrossRef Medline

Jiménez-Díaz L, Géranton SM, Passmore GM, Leith JL, Fisher AS, Berliocchi L, Sivasubramaniam AK, Sheasby A, Lumb BM, Hunt SP (2008) Local translation in primary afferent fibers regulates nociception. PLoS One 3:e1961. CrossRef Medline

Khoutorsky A, Price TJ (2018) Translational control mechanisms in persistent pain. Trends Neurosci 41:100-114. CrossRef Medline

King T, Vera-Portocarrero L, Gutierrez T, Vanderah TW, Dussor G, Lai J, Fields HL, Porreca F (2009) Unmasking the tonic-aversive state in neuropathic pain. Nat Neurosci 12:1364-1366. CrossRef Medline

Kuleshov MV, Jones MR, Rouillard AD, Fernandez NF, Duan Q, Wang Z, Koplev S, Jenkins SL, Jagodnik KM, Lachmann A, McDermott MG, Monteiro CD, Gundersen GW, Ma'ayan A (2016) Enrichr: a comprehensive gene set enrichment analysis web server 2016 update. Nucleic Acids Res 44:W90-W97. CrossRef Medline

Li Y, Adamek P, Zhang H, Tatsui CE, Rhines LD, Mrozkova P, Li Q, Kostura- 
kis AK, Cassidy RM, Harrison DS, Cata JP, Sapire K, Zhang H, KennamerChapman RM, Jawad AB, Ghetti A, Yan J, Palecek J, Dougherty PM (2015) The cancer chemotherapeutic paclitaxel increases human and rodent sensory neuron responses to TRPV1 by activation of TLR4. J Neurosci 35:13487-13500. CrossRef Medline

Li Y, Tatsui CE, Rhines LD, North RY, Harrison DS, Cassidy RM, Johansson CA, Kosturakis AK, Edwards DD, Zhang H, Dougherty PM (2017) Dorsal root ganglion neurons become hyperexcitable and increase expression of voltage-gated T-type calcium channels (Cav3.2) in paclitaxel-induced peripheral neuropathy. Pain 158:417-429. CrossRef Medline

Liu Y, Beyer A, Aebersold R (2016) On the dependency of cellular protein levels on mRNA abundance. Cell 165:535-550. CrossRef Medline

Lopes DM, Denk F, McMahon SB (2017a) The molecular fingerprint of dorsal root and trigeminal ganglion neurons. Front Mol Neurosci 10:304. CrossRef Medline

Lopes DM, Malek N, Edye M, Jager SB, McMurray S, McMahon SB, Denk F (2017b) Sex differences in peripheral not central immune responses to pain-inducing injury. Sci Rep 7:16460. CrossRef Medline

Ma J, Kavelaars A, Dougherty PM, Heijnen CJ (2018) Beyond symptomatic relief for chemotherapy-induced peripheral neuropathy: targeting the source. Cancer 124:2289-2298. CrossRef Medline

Manteniotis S, Lehmann R, Flegel C, Vogel F, Hofreuter A, Schreiner BS, Altmüller J, Becker C, Schöbel N, Hatt H, Gisselmann G (2013) Comprehensive RNA-seq expression analysis of sensory ganglia with a focus on ion channels and GPCRs in trigeminal ganglia. PLoS One 8:e79523. CrossRef Medline

Melemedjian OK, Asiedu MN, Tillu DV, Sanoja R, Yan J, Lark A, Khoutorsky A, Johnson J, Peebles KA, Lepow T, Sonenberg N, Dussor G, Price TJ (2011) Targeting adenosine monophosphate-activated protein kinase (AMPK) in preclinical models reveals a potential mechanism for the treatment of neuropathic pain. Mol Pain 7:70. CrossRef Medline

Melemedjian OK, Khoutorsky A, Sorge RE, Yan J, Asiedu MN, Valdez A, Ghosh S, Dussor G, Mogil JS, Sonenberg N, Price TJ (2013) mTORC1 inhibition induces pain via IRS-1-dependent feedback activation of ERK. Pain 154:1080-1091. CrossRef Medline

Moy JK, Khoutorsky A, Asiedu MN, Black BJ, Kuhn JL, Barragán-Iglesias P, Megat S, Burton MD, Burgos-Vega CC, Melemedjian OK, Boitano S, Vagner J, Gkogkas CG, Pancrazio JJ, Mogil JS, Dussor G, Sonenberg N, Price TJ (2017) The MNK-eIF4E signaling axis contributes to injuryinduced nociceptive plasticity and the development of chronic pain. J Neurosci 37:7481-7499. CrossRef Medline

Moy JK, Khoutorsky A, Asiedu MN, Dussor G, Price TJ (2018) eIF4E phosphorylation influences BDNF mRNA translation in mouse dorsal root ganglion neurons. Front Cell Neurosci 12:29. CrossRef Medline

Obara I, Géranton SM, Hunt SP (2012) Axonal protein synthesis: a potential target for pain relief? Curr Opin Pharmacol 12:42-48. CrossRef Medline

Price TJ, Gold MS (2018) From mechanism to cure: renewing the goal to eliminate the disease of pain. Pain Med 19:1525-1549. CrossRef Medline

Price TJ, Basbaum AI, Bresnahan J, Chambers JF, De Koninck Y, Edwards RR, Ji RR, Katz J, Kavelaars A, Levine JD, Porter L, Schechter N, Sluka KA, Terman GW, Wager TD, Yaksh TL, Dworkin RH (2018) Transition to chronic pain: opportunities for novel therapeutics. Nat Rev Neurosci 19: 383-384. CrossRef Medline

Ray P, Torck A, Quigley L, Wangzhou A, Neiman M, Rao C, Lam T, Kim JY, Kim TH, Zhang MQ, Dussor G, Price TJ (2018) Comparative transcriptome profiling of the human and mouse dorsal root ganglia: an RNA-seqbased resource for pain and sensory neuroscience research. Pain 159: 1325-1345. CrossRef Medline

Reich SH, Sprengeler PA, Chiang GG, Appleman JR, Chen J, Clarine J, Eam B, Ernst JT, Han Q, Goel VK, Han EZ, Huang V, Hung IN, Jemison A, Jessen KA, Molter J, Murphy D, Neal M, Parker GS, Shaghafi M, et al. (2018) Structure-based design of pyridone-aminal eFT508 targeting dysregulated translation by selective mitogen-activated protein kinase interacting kinases 1 and 2 (MNK1/2) inhibition. J Med Chem 61:3516-3540. CrossRef Medline

Richter JD, Sonenberg N (2005) Regulation of cap-dependent translation by eIF4E inhibitory proteins. Nature 433:477-480. CrossRef Medline

Sancak Y, Bar-Peled L, Zoncu R, Markhard AL, Nada S, Sabatini DM (2010) Ragulator-rag complex targets mTORC1 to the lysosomal surface and is necessary for its activation by amino acids. Cell 141:290-303. CrossRef Medline

Saxton RA, Sabatini DM (2017) mTOR signaling in growth, metabolism, and disease. Cell 168:960-976. CrossRef Medline

Seretny M, Currie GL, Sena ES, Ramnarine S, Grant R, MacLeod MR, Colvin LA, Fallon M (2014) Incidence, prevalence, and predictors of chemotherapy-induced peripheral neuropathy: a systematic review and meta-analysis. Pain 155:2461-2470. CrossRef Medline

Soares HP, Ming M, Mellon M, Young SH, Han L, Sinnet-Smith J, Rozengurt E (2015) Dual PI3K/mTOR inhibitors induce rapid overactivation of the MEK/ERK pathway in human pancreatic cancer cells through suppression of mTORC2. Mol Cancer Ther 14:1014-1023. CrossRef Medline

Stirling LC, Forlani G, Baker MD, Wood JN, Matthews EA, Dickenson AH, Nassar MA (2005) Nociceptor-specific gene deletion using heterozygous NaV1.8-cre recombinase mice. Pain 113:27-36. CrossRef Medline

Terenzio M, Koley S, Samra N, Rishal I, Zhao Q, Sahoo PK, Urisman A, Marvaldi L, Oses-Prieto JA, Forester C, Gomes C, Kalinski AL, Di Pizio A, Doron-Mandel E, Perry RB, Koppel I, Twiss JL, Burlingame AL, Fainzilber M (2018) Locally translated mTOR controls axonal local translation in nerve injury. Science 359:1416-1421. CrossRef Medline

Thakur M, Crow M, Richards N, Davey GI, Levine E, Kelleher JH, Agley CC, Denk F, Harridge SD, McMahon SB (2014) Defining the nociceptor transcriptome. Front Mol Neurosci 7:87. CrossRef Medline

Thoreen CC, Chantranupong L, Keys HR, Wang T, Gray NS, Sabatini DM (2012) A unifying model for mTORC1-mediated regulation of mRNA translation. Nature 485:109-113. CrossRef Medline

Ueda T, Watanabe-Fukunaga R, Fukuyama H, Nagata S, Fukunaga R (2004) Mnk2 and Mnk1 are essential for constitutive and inducible phosphorylation of eukaryotic initiation factor $4 \mathrm{E}$ but not for cell growth or development. Mol Cell Biol 24:6539-6549. CrossRef Medline

Usoskin D, Furlan A, Islam S, Abdo H, Lönnerberg P, Lou D, Hjerling-Leffler J, Haeggström J, Kharchenko O, Kharchenko PV, Linnarsson S, Ernfors P (2015) Unbiased classification of sensory neuron types by large-scale single-cell RNA sequencing. Nat Neurosci 18:145-153. CrossRef Medline Uttam S, Wong C, Amorim IS, Jafarnej SM, Tansley SM, Yang J, PragerKhoutorsky M, Mogil JS, Gkogkas CG, Khoutorsky A (2018) Translational profiling of dorsal root ganglia and spinal cord in a mouse model of neuropathic pain. Neurobiol Pain 4:34-44.

Vaso A, Adahan HM, Gjika A, Zahaj S, Zhurda T, Vyshka G, Devor M (2014) Peripheral nervous system origin of phantom limb pain. Pain 155:13841391. CrossRef Medline

Ventzel L, Jensen AB, Jensen AR, Jensen TS, Finnerup NB (2016) Chemotherapy-induced pain and neuropathy: a prospective study in patients treated with adjuvant oxaliplatin or docetaxel. Pain 157:560-568. CrossRef Medline

Wieskopf JS, Mathur J, Limapichat W, Post MR, Al-Qazzaz M, Sorge RE, Martin LJ, Zaykin DV, Smith SB, Freitas K, Austin JS, Dai F, Zhang J, Marcovitz J, Tuttle AH, Slepian PM, Clarke S, Drenan RM, Janes J, Al Sharari S, et al. (2015) The nicotinic alpha6 subunit gene determines variability in chronic pain sensitivity via cross-inhibition of $\mathrm{P} 2 \mathrm{X} 2 / 3$ receptors. Sci Transl Med 7:287ra272. CrossRef Medline

Wolfe AL, Singh K, Zhong Y, Drewe P, Rajasekhar VK, Sanghvi VR, Mavrakis KJ, Jiang M, Roderick JE, Van der Meulen J, Schatz JH, Rodrigo CM, Zhao C, Rondou P, de Stanchina E, Teruya-Feldstein J, Kelliher MA, Speleman F, Porco JA Jr, Pelletier J, et al. (2014) RNA G-quadruplexes cause eIF4A-dependent oncogene translation in cancer. Nature 513:65-70. CrossRef Medline

Wolfson RL, Sabatini DM (2017) The dawn of the age of amino acid sensors for the mTORC1 pathway. Cell Metab 26:301-309. CrossRef Medline

Yang Q, Wu Z, Hadden JK, Odem MA, Zuo Y, Crook RJ, Frost JA, Walters ET (2014) Persistent pain after spinal cord injury is maintained by primary afferent activity. J Neurosci 34:10765-10769. CrossRef Medline

Yilmaz E, Gold MS (2016) Paclitaxel-induced increase in NCX activity in subpopulations of nociceptive afferents: a protective mechanism against chemotherapy-induced peripheral neuropathy? Cell Calcium 60:25-31. CrossRef Medline

Zhou P, Zhang Y, Ma Q, Gu F, Day DS, He A, Zhou B, Li J, Stevens SM, Romo $\mathrm{D}, \mathrm{Pu}$ WT (2013) Interrogating translational efficiency and lineagespecific transcriptomes using ribosome affinity purification. Proc Natl Acad Sci U S A 110:15395-15400. CrossRef Medline 